\title{
Characterization of Microstructure and Mechanical Properties in Two Different Nanostructured Bainitic Steels
}

\author{
$\underline{\text { Behzad Avishan }}^{* a}$, Sasan Yazdani ${ }^{\mathrm{b}}$, Francisca G. Caballero ${ }^{\mathrm{c}}$, \\ Tiansheng Wang ${ }^{\mathrm{d}}$, Carlos Garcia-Mateo ${ }^{\mathrm{c}}$
}

a) Department of Materials Engineering, Azarbaijan Shahid Madani University, Tabriz, Iran.

b) Faculty of Materials Engineering, Sahand University of Technology, Tabriz, Iran.

c) MATERALIA Research Group, Department of Physical Metallurgy, Centro Nacional de Investigaciones Metalurgicas (CENIM-CSIC), Madrid, Spain.

d) State Key Laboratory of Metastable Materials Science and Technology, Yanshan University, Qinhuangdao 066004, China.

*Corresponding author: Behzad Avishan, Email: avishan@ azaruniv.edu

Address: Department of Materials Engineering, Azarbaijan Shahid Madani University, Tabriz, Iran. tel.: 00984134327500 (2491)

\begin{abstract}
Recently, valuable combinations of mechanical properties with strength of $1.9 \mathrm{GPa}$ accompanied by very decent ductility of $19 \%$ and toughness of $31 \mathrm{~J}$, have been achieved in a set of nanostructured bainitic steels. However, it is necessary to elucidate the significance of various microstructural features responsible of that extraordinary mechanical response in more detail. Thus, using two steels, with different $\mathrm{Mn}, \mathrm{Ni}$ and $\mathrm{V}$ contents, and changing the nanostructured bainite isothermal transformation temperatures $\left(200-300^{\circ} \mathrm{C}\right)$, has led to a plethora of subtle and essential microstructural variations, necessary to explain how the mechanical response of nanostructured bainite is attained.
\end{abstract}

\section{Keywords}

Nanostructured bainite; Mechanical properties; TEM; XRD; SEM. 


\section{Introduction}

The valuable combination of strength and ductility properties in nanostructured bainitic steels, has awaken the interest of different industrial sectors and nowadays they are under development in various markets ${ }^{1-9}$. The dominant phase in this group of high strength steels is bainitic ferrite with typical plate morphology of just a few tens of nanometer thickness intimately interweaved with thin films of high carbon retained austenite. The mechanism by which bainite forms is displacive and diffusionless adding more unique features to the microstructure such as high dislocation density, nano twins, heterogeneous $\mathrm{C}$ distribution in austenite and etc. ${ }^{10,11}$.

Toughness in this type of microstructure is mainly controlled by high carbon retained austenite, which has been clarified before by Avishan et.al during their primary investigations on different variations of nano bainite with similar chemical compositions to those presented in this study ${ }^{12}$. Moreover, when explaining the strength of the low temperature bainite, it must be turned to the hardest phase in the microstructure, i.e. bainitic ferrite. Without doubt, the reported high strength levels are related to both volume fraction and scale of the bainitic ferrite and also the dislocation density introduced during the transformation process ${ }^{13,14}$. Other factors such as the $\mathrm{C}$ trapped in dislocations and twins or the amount of $\mathrm{C}$ that remains in solid solution must also play a decisive role in the strength of nanostructured bainite. However, the role of high carbon retained austenite in strength properties cannot be ignored. It is well known that the TRIP effect (transformation induced plasticity) is a very important factor enhancing the ultimate tensile strength and uniform elongation simultaneously in steels containing high carbon retained austenite within their microstructure at room temperature, e.g. nanostructured bainite. During the plastic deformation of such microstructure, retained austenite changes to martensite from nucleation sites created by strain, TRIP effect, beside those potential sites for nucleation of athermal martensite ${ }^{15}$. Thus, replacing the ductile austenite with hard martensite can further increase the strength level. In addition, the plastic deformation accompanying the displacive 
martensitic transformation generates a high dislocation density which in turn increases the work hardening rate ${ }^{16}$. Thus TRIP effect can influence the mechanical properties by affecting the work hardening and delaying the necking during straining the sample ${ }^{17-20}$. This is the point where the mechanical stability of retained austenite must be considered. Avishan et.al studied the various important factors affecting the austenite mechanical stability in nanostructured bainite obtained at $200{ }^{\circ} \mathrm{C}$ in another study and results have been published elsewhere ${ }^{21}$. They showed that this criterion plays a crucial role in controlling the TRIP effect.

However, very detailed microstructural characterizations are mandatory to elucidate the strength - ductility combination and to recognize the controlling parameters, which is the case in the present study. There are quite a few numbers of identified factors that play a conclusive role, such as chemical composition, primary austenite grain size and morphology and distribution of microstructural constituents $5,22-30$. This article aims to investigate and characterize some of the most exceptional and unique microstructural features obtained in two nanostructured bainitic steels with different amounts of $\mathrm{Ni}, \mathrm{Mn}$ and $\mathrm{V}$ to study how they contribute to respective final mechanical response in more detail.

\section{Experimental methods}

Primary ingots were cast in an induction furnace under inert $\mathrm{Ar}$ atmosphere. Steels were electro slag remelted and then homogenized at $1200{ }^{\circ} \mathrm{C}$ for $2 \mathrm{~h}$, and then hot rolled at a temperature of about $950{ }^{\circ} \mathrm{C}$ in several passes to sheets of $15 \mathrm{~mm}$ thickness with chemical composition of given in Table 1. The chemical compositions were designed based solely on bainitic phase transformation theory ${ }^{11}$ and assisted by MUCG83 ${ }^{\mathrm{TM}}$, a suite of software for modeling of the thermodynamics and kinetics of solid - state transformations in steels ${ }^{31}$. A recent review on the steps followed to design such type of alloys is given elsewhere ${ }^{32-35}$. Suffice to note that, the 
amount of Mn and Ni significantly varies in two alloys, as they were designed to have almost identical TTT and $\mathrm{T}_{\mathrm{o}}$ diagrams ${ }^{10,11}$. Besides, small quantities of $\mathrm{V}$ were also added in steel 2 to restrict prior austenite grain size growth during the austenitizing heat treatment by pinning the grain boundaries with $\mathrm{V}(\mathrm{CN})$. Note that, $\mathrm{Si}$ addition in such quantities is enough to ensure the absence of cementite within the microstructure ${ }^{11}$.

Table 1- Chemical composition of cast alloys (wt.\%).

\begin{tabular}{cccccccccc}
\hline alloy & $\mathbf{C}$ & Si & Mn & Ni & Mo & Cr & V & Co & Al \\
\hline Steel 1 & 0.91 & 1.58 & 1.98 & 0.06 & 0.25 & 1.12 & 0 & 1.37 & 0.53 \\
Steel 2 & 0.90 & 1.51 & 0.94 & 2.61 & 0.25 & 1.14 & 0.09 & 1.37 & 0.59 \\
\hline
\end{tabular}

Pieces of both alloys were austenitized at $900{ }^{\circ} \mathrm{C}$ for $30 \mathrm{~min}$ in salt bath furnaces (after $\mathrm{Ac}_{3} \approx 845$ ${ }^{\circ} \mathrm{C}$, determined using high resolution dilatometer). Immediately after, samples were transferred to another salt baths at 300,250 and $200{ }^{\circ} \mathrm{C}$ and held isothermally until the bainitic transformation completed. The time needed to complete the transformation at above temperatures ranged from about $10 \mathrm{~h}$ at $300{ }^{\circ} \mathrm{C}$ to 3 days at $200{ }^{\circ} \mathrm{C}$. Note that all the chosen temperatures were above the experimentally determined Ms temperature of $114^{\circ} \mathrm{C}$.

Primary austenite grain size at the austenitizing temperature was determined using thermal etching method as described previously ${ }^{36,37}$. Detailed microstructural characterizations were carried out using a Hitachi S- $4800^{\mathrm{TM}}$ field emission gun scanning electron microscope (FEGSEM), operating at $7 \mathrm{kV}$, after grinding, polishing and etching the samples with $2 \%$ nital etching solution following the standard procedure. High magnification FEG- SEM micrographs were evaluated to determine the size of the bainitic plates, austenite films and austenite blocks using the line intercept method ${ }^{33,38}$. TEM studies were conducted to perform a precise microstructural evaluation where specimens were sliced from $3 \mathrm{~mm}$ diameter rods of heat treated material, mechanically thinned to $0.06 \mathrm{~mm}$ and then twin - jet electro polished to perforation using a 
mixture of 5\% perchloric acid, $25 \%$ glycerol and $70 \%$ ethanol at $-6{ }^{\circ} \mathrm{C}$ and $45 \mathrm{~V}$. samples were studied on a TEM JEOL $2100^{\mathrm{TM}}$ transmission electron microscope operating at $200 \mathrm{kV}$.

Quantitative X- ray diffraction analysis was used to determine the volume fraction of retained austenite $\left(\mathrm{V}_{\gamma}\right)$ and its carbon content $\left(\mathrm{C}_{\gamma}\right)$. For this aim, samples were machined; ground and finally polished using $1 \mu \mathrm{m}$ diamond paste, then subjected to several cycles of etching and polishing to obtain an undeformed surface and were finally polished in colloidal silica. They were then step scanned in a Brucker - Axs D8 X- ray diffractometer using unfiltered Co Ka radiation. The scanning speed $(2 \theta)$ was less than 0.3 degree/min and machine was operated at 40 $\mathrm{kV}$ and $30 \mathrm{~mA}$. The volume fraction of retained austenite was calculated from the integrated intensities of (111), (200), (220), and (311) austenite peaks and those of (110), (200), and (211) peaks of ferrite. Using this number of peaks avoids possible bias due to crystallographic texture ${ }^{39}$. Accurate austenite lattice parameter and its chemical composition were determined by means of Rietveld method ${ }^{40}$ and Dyson and Holmes 's equation ${ }^{41}$, respectively. X- ray data were also

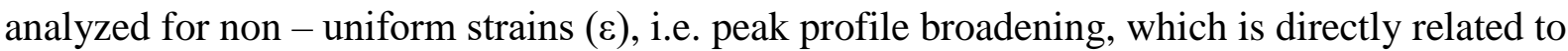
the dislocation density ${ }^{42,43}$. Highlight that in bainitic transformation, nucleation takes place under paraequilibrium conditions (only $\mathrm{C}$ diffuses) and its growth is diffusionless. When using the lattice parameter to work out the $\mathrm{C}$ concentration, the concentration ratios of all elements except $\mathrm{C}$ should be equal in the bulk material as in the retained austenite $(\gamma)$, i.e. $\left(\mathrm{x}_{\mathrm{Fe}} / \mathrm{x}_{\mathrm{j}}\right)_{\text {bulk }}=$ $\left(\mathrm{x}_{\mathrm{Fe}} / \mathrm{x}_{\mathrm{j}}\right) \gamma$, where $\mathrm{j}$ denotes any substitutional element in the alloy, and $\mathrm{x}_{\mathrm{Fe}}$ and $\mathrm{x}_{\mathrm{j}}$ are the concentrations of $\mathrm{Fe}$ and the substitutional elements, respectively ${ }^{26}$.

Flat tensile samples with $9.8 \mathrm{~mm}$ gage lengths were cut and machined from primary sheets according to JIS Z2201 standard and all were heat treated as described before. Tensile tests were performed using a Micro Test EM2/100/FR ${ }^{\mathrm{TM}} \mathrm{T} 3053$ series test instrument fitted with a $100 \mathrm{kN}$ load cell. All experiments were assisted by an extensometer fitted to electronic equipment that 
allowed the continuous tracking of load - displacement data during the tests. At least three specimens were used for each tensile test to ensure the reproducibility. Charpy impact tests were conducted at room temperature using notched samples with $10 \times 10 \times 55 \mathrm{~mm}^{3}$ dimensions and reported values are average of at least 4 measurements. Finally, all the necessary thermodynamic calculations were performed by means of $\mathrm{MTDATA}^{\mathrm{TM}}$, with the NPL-plus database for steels ${ }^{44}$ , in order to calculate the chemical free energy change for the transformation of austenite to ferrite of the same composition and corresponding $\mathrm{M}_{\mathrm{d}}$ temperatures based on the method described before by Sherif et al ${ }^{45}$. Note that, these calculations must use the chemical composition of retained austenite calculated as already described.

\section{Results and discussions}

\section{1. Detailed microstructural characterization}

As anticipated, the microstructure is dual in phase, in the sense that bainitic ferrite and high carbon retained austenite are the only constituents and the magnitude of the latter decreases at lower transformation temperature; see the $\mathrm{X}$ - ray profile analyses in Fig. 1 and the corresponding experimental quantitative data in Table 2. Fig. 2 illustrates the microstructural characteristics at different transformation temperatures, where increasing the volume fraction of the retained austenite, darker phase, is very evident when the transformation temperature increases from 250 to $300{ }^{\circ} \mathrm{C}$. It is clear from Table 2 and Figure 2 that those differences are more subtle when comparing the 200 and $250{ }^{\circ} \mathrm{C}$ microstructures.

Detailed comparison of (111) and (200) austenite diffraction peaks of each profile reveals that not only the peaks gain an intensity with increasing the transformation temperature, but also they shift towards smaller $2 \theta$ values. It means that the volume fraction of the retained austenite, 
its lattice parameter and the $\mathrm{C}$ in solid solution increases with enhancing the transformation temperature. These results can be misleading, as this trend is not that expected from the theory where the $T_{0}$ diagram predicts an enrichment of the austenite with $\mathrm{C}$ as the transformation temperature decreases. However, this can be explained keeping in mind that the dislocations and twins introduced during the plastic relaxation accompanying the bainitic transformation, are capable of trapping $\mathrm{C}$ atoms and therefore preventing the decarburization of super-saturated bainitic ferrite ${ }^{10,46-51}$ where the density of such microstructural defects increases as the transformation temperature decreases ${ }^{46,52,53}$. Selected TEM micrographs are presented in Fig. 3 depicting not only the scale of the microstructure but also the intense dislocation debris evident in both bainitic ferrite and high carbon retained austenite which has been also shown by the authors before for the same steels ${ }^{54}$. Moreover, Fig. 4 shows an example of the accommodation twins in austenite, presence of which has been discussed before by Caballero et.al ${ }^{46}$. Table 2 gathers the estimation of the dislocation density after $\mathrm{X}$ - ray profile analysis in terms of the peak broadening and corresponding microstrain associated with dislocations formation during bainitic transformation. As expected, the dislocation density increases as the transformation temperature decreases and all are well above those measured for more conventional bainite and allotriomorphic ferrite ${ }^{55}$. Again, differences are more evident when increasing the transformation temperature from 250 to $300^{\circ} \mathrm{C}$, and more subtle from 200 to $250^{\circ} \mathrm{C}$. In general terms, the results presented here are analogous to those measured in similar alloys ${ }^{50,51}$. Back to Fig. 1, it is also very distinguishable that the peaks are broadened when the transformation temperature decreases. The source of the broadening is a conjunction of mainly two sources. First the nano - sized retained austenite particles and the second the local lattice strain, again effect of both increases as the transformation temperature decreases. However, there is another factor making austenite reflection peaks more broadened which is the variations of the $\mathrm{C}$ concentration in the volume sampled by the $\mathrm{X}$ - ray beam, a feature inherent to the 
bainitic transformation. This broadening is asymmetric and although affects all peaks of austenite, it increases with diffraction angle, see for example (220) and (311) peaks of austenite. Thin films and blocks are two essential morphologies of austenite in silicon reach bainitic steels each contains different quantities of $\mathrm{C}$ in solid solution. The $\mathrm{C}$ enrichment is greatest in the vicinity of the bainitic plates, with distant austenite affected little, thus giving rise to the broadening due to the different austenite lattice parameters ${ }^{52,56}$. That turns into austenite films entrapped between neighbor plates of bainitic ferrite having higher carbon content than the austenite blocks bound by crystallographic variants of bainite, sheaves, and exhibiting polygonal shape in two dimensional sections ${ }^{57}$. Examples of both types of morphologies are identified in Fig. 2 and Fig. 3. There are experimental evidences clearly indicating that in certain austenite regions the measured $\mathrm{C}$ concentration exceeds the value corresponding to $\mathrm{T}_{\mathrm{o}}$ diagram which is the theoretical limit reached once the bainitic transformation is completed ${ }^{32}$. Although such austenite can no longer transform to bainite but it can continue to accumulate $\mathrm{C}$ from suitable sources. Such circumstances arise naturally during bainite reaction when a region of austenite, which has been affected by the dumping of carbon from an extant bainite plate, becomes isolated by the formation of new super-saturated bainite plates in its close proximity. The subsequent partitioning of $\mathrm{C}$ from these initially super-saturated bounding plates can raise the $\mathrm{C}$ content of the entrapped austenite film to any level ranging between the $\mathrm{T}_{\mathrm{o}}$ and the Ae3 value ${ }^{32}$.

Table 2 - Quantitative characterization data for the microstructures after isothermal treatment at different temperatures where $V \alpha_{b}, V \gamma_{f}$ and $V \gamma_{b}$ represent the volume fraction of bainitic ferrite, and retained austenite films and blocks, respectively. $\mathrm{C} \gamma$ is the austenite carbon content and $\rho_{\gamma}$ and $\rho_{\alpha}$ are the dislocation densities in austenite and bainitic ferrite.

\begin{tabular}{|c|c|c|c|c|c|c|}
\hline \multirow[b]{3}{*}{$V \boldsymbol{\alpha}_{\mathbf{b}}$} & \multicolumn{2}{|c|}{$200^{\circ} \mathrm{C}$} & \multicolumn{2}{|c|}{$250^{\circ} \mathrm{C}$} & \multicolumn{2}{|c|}{$300{ }^{\circ} \mathrm{C}$} \\
\hline & Steel 1 & Steel 2 & Steel 1 & Steel 2 & Steel 1 & Steel 2 \\
\hline & $58 \pm 3$ & $67 \pm 3$ & $57 \pm 3$ & $63 \pm 3$ & $46 \pm 3$ & $56 \pm 3$ \\
\hline $\mathrm{C}_{\gamma}(\mathrm{wt} \%)$ & $1.01 \pm 0.1$ & $1.07 \pm 0.1$ & $1.29 \pm 0.1$ & $1.35 \pm 0.1$ & $1.26 \pm 0.1$ & $1.45 \pm 0.1$ \\
\hline $\boldsymbol{\rho}_{\gamma}\left(\mathbf{m}^{-2}\right)$ & $6.88 \times 10^{15}$ & $8.98 \times 10^{15}$ & $6.85 \times 10^{15}$ & $7.85 \times 10^{15}$ & $3.49 \times 10^{15}$ & $5.02 \times 10^{15}$ \\
\hline$\rho_{\alpha}\left(\mathrm{m}^{-2}\right)$ & $1.13 \times 10^{16}$ & $1.13 \times 10^{16}$ & $9.52 \times 10^{15}$ & $9.52 \times 10^{15}$ & $7.3 \times 10^{15}$ & $7.29 \times 10^{15}$ \\
\hline$V \gamma_{f}$ & $9 \pm 0.4$ & $10 \pm 0.4$ & $8 \pm 0.4$ & $9 \pm 0.4$ & $7 \pm 0.4$ & $9 \pm 0.4$ \\
\hline$V \gamma_{b}$ & $33 \pm 3$ & $23 \pm 3$ & $35 \pm 3$ & $28 \pm 3$ & $47 \pm 3$ & $35 \pm 3$ \\
\hline
\end{tabular}


Another interesting fact is that there is an enhancement of thin film morphology as opposed to blocky austenite with decreasing the transformation temperature. The estimation of the volume fraction of each morphology can be done based on the proposal that filmy austenite consists of almost $15 \%$ of a bainite sheaf according to Bhadeshia and Edmonds ${ }^{13}$. Such results are presented in Table 2, where it is clear that the highest volume fraction of thin films of retained austenite can be reached below $300{ }^{\circ} \mathrm{C}$. The small differences between the 200 and the $250{ }^{\circ} \mathrm{C}$, are in accordance with those detected in $\mathrm{V}_{\mathrm{ab}}$.

Even though both steels were designed to have the same fraction of bainitic ferrite at a given temperature, i.e. same $T_{0}$ curve, results show that steel 2 contains more bainitic ferrite. It has been shown that under appropriate circumstances a reduction of the prior austenite grain size can increase the volume fraction of bainitic ferrite ${ }^{38}$ which is the case of steel 2 in this study. Results indicate that the size of the primary austenite grains decreased from $37 \pm 1 \mu \mathrm{m}$ in steel 1 to $20 \pm 2 \mu \mathrm{m}$ in steel 2 because of the pinning of the grain boundaries by $\mathrm{V}(\mathrm{CN})$.

Extensive TEM observations, Fig. 3, showed that the microstructures are essentially carbide free as expected from addition of $1.5 \mathrm{wt} \% \mathrm{Si}$. Also it has been revealed that there is a well - known rational Kurdjumov - Sachs $(\mathrm{K}-\mathrm{S})$ orientation relationship with $\{111\} \gamma / /\{110\} \alpha$ and $<110>$ $\gamma / /<111>\alpha$ between bainitic ferrite and parent austenite which has been also confirmed before $10,11,58$. The same micrographs offer a more accurate idea of the scale of the microstructure dealing with. Corresponding measurements, Table 3, showed that the low transformation temperatures result in nano scaled bainitic ferrite with apparent thicknesses ranging from 39 70 and $35-67 \mathrm{~nm}$ for steel 1 and steel 2, respectively. Decreasing the transformation temperature increases the dislocation density after yielding the austenite which is found to be the major reason in combination with the higher strength of the austenite refining the bainitic ferrite plates 59,60 . Therefore, it is not strange that when strong solid solution hardeners are present in the austenite, the bainite growth results in even finer plates. In this sense, elements such as $\mathrm{C}, \mathrm{Si}$, 
Mn, and Ni are known for strength capacity in solid solution ${ }^{61,62}$. The thickness of the bainitic ferrite plates must also be influenced by impingement between adjacent plates. So far a more volume fraction of bainitic ferrite due to the higher nucleation rate and smaller prior austenite grain size, should correspond to a finer microstructure ${ }^{38,63}$ and this is the case when comparing steel 1 and steel 2 in this study. Fig. 5 illustrates the apparent plate thickness distribution at all transformation temperatures for both steels. The lack of "thick plates" tale in such distribution, for example at $200{ }^{\circ} \mathrm{C}$ after 3 days, can be interpreted as an indirect evidence that the strength of austenite is the main source of resistance to interface motion. Or otherwise the first plates in appearing, usually within a few hours, would have thickened during the remainder of such heat treatment. Thin films of retained austenite also exhibit a nano scale, $38-62$ and $30-45 \mathrm{~nm}$ in each steels respectively, with almost similar distribution in Fig. 6, because they are plastically constrained by surrounding plates of bainitic ferrites.

Table 3- Quantitative data on the scale of the microstructure attained after different heat treatment conditions, where $\mathrm{t}$ stands for the apparent plate thickness $(\mathrm{nm})$ of the indicated phases and morphologies.

\begin{tabular}{c|cc|cc|cc|}
\hline \multicolumn{2}{c}{$200{ }^{\circ} \mathbf{C}$} & \multicolumn{2}{c}{$\mathbf{2 5 0}^{\circ} \mathbf{C}$} & \multicolumn{2}{c}{$300{ }^{\circ} \mathbf{C}$} \\
\cline { 2 - 7 } & Steel 1 & Steel 2 & Steel 1 & Steel 2 & Steel 1 & Steel 2 \\
$\mathbf{t} \boldsymbol{\alpha}_{\mathbf{b}}$ & $39 \pm 2$ & $35 \pm 1$ & $50 \pm 2$ & $53 \pm 2$ & $70 \pm 3$ & $67 \pm 2$ \\
$\mathbf{t} \boldsymbol{\gamma}_{\mathbf{f}}$ & $38 \pm 2$ & $30 \pm 1$ & $44 \pm 2$ & $42 \pm 1$ & $62 \pm 3$ & $45 \pm 1$ \\
$\mathbf{t} \boldsymbol{\gamma}_{\mathbf{b}}$ & $808 \pm 22$ & $598 \pm 23$ & $1005 \pm 31$ & $807 \pm 25$ & $1644 \pm 63$ & $1126 \pm 117$ \\
\hline
\end{tabular}

Referring to Fig. 7 and the corresponding analytic data in Table 3 regarding the austenite block sizes, there are some noticeable differences. Austenite blocks in steel 2 are significantly more refined and have a narrower distribution comparing to that of steel 1, being coherent with a higher volume fraction of bainitic ferrite. Additionally, the smaller prior austenite grains in steel 2 would also contribute to have a smaller austenite blocks, where almost 26,20 and $31 \%$ of size reduction has been detected at 200,250 and $300{ }^{\circ} \mathrm{C}$ in this case, respectively. 
There are some other microstructural features that although they are not characterized in this study, but they are relevant for future discussion of the mechanical properties of these microstructures. For instance, results indicated that the $\mathrm{C}$ concentration in bainitic ferrite was much higher than that expected from paraequilibrium thermodynamics between austenite and ferrite ${ }^{2,64}$. This super saturation was attributed to the trapping of $\mathrm{C}$ at dislocations in bainitic ferrite, as those Cottrell atmospheres ${ }^{47-49}$. But a recent finding showed that large quantities of C remain in solid solution in defect - free regions of the microstructure ${ }^{64,65}$. These results rationalized that low transformation heat treatment causes the ferrite unit cell to be non - cubic but tetragonal, with much higher $\mathrm{C}$ solubility, and experimental evidences is now available using high resolution TEM and $\mathrm{X}$ - ray diffraction ${ }^{66,67}$.

\section{2. Mechanical properties}

Fig. 8 shows the engineering stress - engineering strain curves derived from the tensile tests for every microstructure and the average values of $0.2 \%$ off set yield stress (YS), ultimate tensile stress (UTS), uniform elongation (UEL) and total elongation (TEL) are given in Table 4. The continuous yielding behavior is observed, similar to that of high strength dual phase steels, which is attributed mainly to the high dislocation density introduced during the bainitic transformation. There are a variety of obstacles to dislocation motion such as phase interfaces and thin films of retained austenite. However, many of the obstacles are not uniformly distributed, so obstacle free areas are still existed into which dislocations can penetrate at low stresses and giving rise to gradual yielding.

According to the tensile test results in Table 4, UTS values are ranging from 1.6 to $2.2 \mathrm{GPa}$ corresponding to the microstructures obtained at the highest and the lowest transformation temperatures, respectively. Such strength levels are accompanied with non - negligible ductility, 
for example $11 \%$ of UEL for UTS of almost $2.2 \mathrm{GPa}$ in steel 2 . Strength is mainly controlled by the amount and the scale of the harder phase, bainitic ferrite in these groups of steels. In general, strength correlates well with the ratio of $V \alpha_{b} / t \alpha_{b}$, see Fig. 9 (a). The higher the volume fraction of the thinner bainitic ferrite plates are, the higher the YS and UTS values will be. The Longford type bainitic ferrite plate contribution to strength, $\left(\operatorname{ta}_{b}\right)^{-1} 68,69$, instead of the typical Hall - Petch $\left(t \alpha_{b}\right)^{-1 / 2}$, is used because of the grain size being well below the sub - micrometer where the mechanism of the yielding involves the initiation of dislocation sources in the grain boundaries.

Other operative strengthening mechanisms contributing to the strength are the dislocation density, chemical composition, excess of $\mathrm{C}$ in solid solution, and although more difficult to quantify, the contribution of the Cottrell atmospheres through its effect on the mobility of dislocations. Qualitatively, this is evident when comparing the microstructures of steels at each temperature of 250 and $300^{\circ} \mathrm{C}$, where a higher fraction of hard and fine bainitic ferrite is not always solely analogous of higher YS.

Table 4- Quantitative mechanical properties data derived from engineering stress - engineering strain curves of shown in Fig. 8 and impact test results obtained at room temperature.

\begin{tabular}{c|cc|cc|cc|}
\hline \multicolumn{1}{c}{} & \multicolumn{2}{c}{$\mathbf{2 0 0}^{\circ} \mathbf{C}$} & \multicolumn{2}{c}{$\mathbf{2 5 0}^{\circ} \mathbf{C}$} & \multicolumn{2}{c}{$\mathbf{3 0 0}^{\circ} \mathbf{C}$} \\
\cline { 2 - 7 } YS (MPa) & Steel 1 & Steel 2 & Steel 1 & Steel 2 & Steel 1 & Steel 2 \\
UTS (Mpa) & $1405 \pm 30$ & $1730 \pm 40$ & $1321 \pm 20$ & $1283 \pm 15$ & $1080 \pm 20$ & $1093 \pm 25$ \\
UEL & $2115 \pm 30$ & $2182 \pm 50$ & $1818 \pm 20$ & $1893 \pm 20$ & $1592 \pm 20$ & $1639 \pm 25$ \\
TEL (\%) & $8 \pm 2$ & $11 \pm 2$ & $11 \pm 2$ & $16 \pm 2$ & $22 \pm 2$ & $29 \pm 2$ \\
Impact energy (J) & $8 \pm 2$ & $14 \pm 2$ & $14 \pm 2$ & $19 \pm 2$ & $27 \pm 2$ & $32 \pm 2$ \\
\hline
\end{tabular}

On the other hand, austenite can affect the strength properties by transforming to martensite during the tensile test through the TRIP effect. Thus, the introduction of new dislocations as a consequence of the martensitic transformation and the presence of this new strong phase represent two reasons for the "indirect" effect of retained austenite on increasing the strain hardening rate of the microstructure. 
Accepting the subtle differences between the 200 and $250^{\circ} \mathrm{C}$ phase fractions, a very simplistic analysis of data in Table 2 and Table 4 would lead to the conclusion that austenite itself is controlling the ductility of these microstructures. For given steel, the ductility improves by increasing the transformation temperature and its austenite volume fraction. But the same reasoning does not applicable when comparing both steels at the same transformation temperature. For example, at $200{ }^{\circ} \mathrm{C}$, steel 1 does not exhibit better, but lower, ductility despite of its $10 \%$ more austenite within the microstructure comparing to steel 2 . Somehow, the mechanical stability of retained austenite and its ability to transform to martensite by TRIP effect should be considered as well. Attending purely to the strong effect that $\mathrm{C}$ has on enhancing the mechanical stability of retained austenite, a kind of stability factor can be defined as $\mathrm{C}_{\gamma} \times \mathrm{V}_{\gamma}$. According to Fig. 9 (b), it is clarified that the more stable the austenite is, the better the ductility behavior will be. But the dispersion found in some of the results clearly indicates that the problem is far more complex.

TRIP effect is known to take place between the $\mathrm{M}_{\mathrm{s}}$ and $\mathrm{M}_{\mathrm{d}}$ temperatures of the retained austenite. The mechanical stability increases by increasing the testing temperature above $\mathrm{M}_{\mathrm{s}}$ and it becomes completely stable at temperatures more than $\mathrm{M}_{\mathrm{d}}$. In other words, lower $\mathrm{M}_{\mathrm{d}}$ temperature equals to mechanically more stable austenite in the case of testing at room temperature. From a pure chemical composition point of view, the $\mathbf{M}_{\mathrm{d}}$ temperature is strongly controlled by C, N, Ni, Mn, Cr, Si, Mo and Al, in decreasing order of importance ${ }^{45,49,70,71}$. In our case, the $\mathrm{M}_{\mathrm{d}}$ temperatures of steel 2 at 200,250 and $300{ }^{\circ} \mathrm{C}$, are 387,277 and $307^{\circ} \mathrm{C}$ which are all lower than that of steel $1,437,357$ and $357^{\circ} \mathrm{C}$, at each transformation temperature, respectively.

It is also well reported that the reduction of the size of the retained austenite is a critical stabilization factor and the smaller grain sizes makes it more stable ${ }^{67,72}$. It has been suggested that the grain size of the retained austenite should be in the range of 0.01 to $1 \mu \mathrm{m}$ to ensure an 
effective TRIP effect ${ }^{73}$ where the smaller particles are too stable to undergo the strain - induced transformation. The reasons lying beneath are several. First, constrains exerted by the surrounding plates of bainitic ferrites may even halt the martensitic transformation. Second, the smaller retained austenite films contain lower potential nucleation sites for the formation of martensite therefore requiring higher driving force for the transformation ${ }^{74,75}$. Finally, smaller grains are supper saturated in C. In a similar manner, given that austenite to martensite transformation involves the coordinated movement of atoms, the motion of glissile interfaces becomes impossible when the defect density is high enough, meaning that dislocations present in the microstructure together with those introduced by the TRIP effect, provokes a hardening of the surrounding matrix. This makes it more resistant to deformation and further transformation may be impossible as the volume increase can no longer be accommodated by deformation. Hence, the strength of the retained austenite and the matrix are also playing an important role. There is still another mechanism by which the matrix can affect the stability of the retained austenite known as stress shielding which is based on the assumption that bainitic ferrite in this microstructure is significantly harder than retained austenite and in such a composite microstructure, austenite experiences less stresses ${ }^{76,77}$. In this sense, in situ neutron diffraction analysis during the tensile test at room temperature has confirmed that the contribution of the nanostructured bainitic ferrite obtained by transformation at $200{ }^{\circ} \mathrm{C}$ to the microstructure's ductility is almost null as it hardly deforms. What is more, such strong matrix forces the retained austenite to cope with most of the plastic deformation leading to premature and ineffective TRIP effect. On the other hand, if the microstructure is obtained at higher temperatures, $300{ }^{\circ} \mathrm{C}$, and the corresponding strength difference between both phases is not so marked, the behavior in terms of ductility and TRIP effect is much better ${ }^{78}$.

Fig. 10 displays the instantaneous hardening exponent (n) behavior with the true strain for both steels obtained at each transformation temperature. It reflects the dynamic transformation 
behavior of the retained austenite during straining. What is more, there is a common feature for all the analyzed microstructures, and it is the fact that plastic deformation is uniformly distributed along the gauge length of the samples, showing little necking or not at all. In other words, most or all of the total elongation achieved was uniform, see Table 4. Considering the samples transformed at $200{ }^{\circ} \mathrm{C}$, the instantaneous exponent curve in steel 1 renders a continuous increase toward the instability criteria, straight line, which is never reached, which means that all the elongation was uniform. However, in the case of steel 2, there is a more progressive evolution of the same exponent up to necking after a rapid increase. This behavior differs to that found in other microstructures where there is sustenance of " $n$ " value after a rapid decrease. In the case of the 250 and $300{ }^{\circ} \mathrm{C}$ microstructures, there is a spectacular recovery of the hardening exponent, more typical of some TRIP - aided steels and even TWIP steels ${ }^{79}$.

For the particular case of the $200{ }^{\circ} \mathrm{C}$ microstructure, interrupted tensile tests were conducted and samples were analyzed further in detail considering the microstructural parameters, chemical composition, morphology and size distribution of the constituents, the results of which were published elsewhere $^{21}$. It was found that, the superior ductility in steel 2, compared to that of steel 1, was a direct consequence of the mechanically more stable retained austenite. Results showed that there was almost $30 \%$ of untransformed retained austenite right before rupture in steel 1, which could be only explained due to the higher strength of austenite and bainitic ferrite, as replacing $\mathrm{Mn}$ by $\mathrm{Ni}$, with much lower solid solution strengthening capacity in steel 2 . This hinders the austenite to martensite transformation (TRIP effect) ${ }^{57,80}$. As expected, this remains valid for new tested microstructures obtained by transformation at 250 and $300{ }^{\circ} \mathrm{C}$. In general, when comparing the same microstructures for both steels, the retained austenite in steel 1 is found to be poorer in $\mathrm{C}$, less dislocated and bigger in size with a wider size distribution, which in principle should lead to a more effective TRIP effect. However, despite this and the fact that the volume fraction of the retained austenite is higher than that of steel 2, it can be speculated, 
based on the " $n$ " curves, that steel 2 has a more effective TRIP effect through the whole range of the plastic deformation, because of the higher mechanical stability of its austenite allowing for an increase in the strain hardening and consequently deterring the plastic instability or necking. Accordingly, it is very illustrative that up to $\sim 0.025$ of true strain, both steel 1 and steel 2 treated at $250{ }^{\circ} \mathrm{C}$ and $300{ }^{\circ} \mathrm{C}$ behave almost identically. Afterwards, steel 2 shows not only higher "n" values but also a more progressive recovery of the initial "n" referring to higher UTS values. The fact that a higher fraction of hard and fine bainitic ferrite is not always analogous of higher YS is another argument supporting the idea of stabilized austenite due to a stronger matrix in the case of steel 1.

Considering the toughness variations, the amount of the retained austenite within the microstructure should play a critical role through its crack blunting effect, the stress-relief and the martensite transformation ahead of the cracks ${ }^{81}$. It has been reported that there is an improvement of toughness if TRIP effect of moderately stable austenite takes place at the tip of the crack. Although in this type of microstructures, the tendency of the newly formed martensite to crack might also depends on its absolute size but, if TRIP effect takes place in more stable austenite (richer in C) the newly formed high carbon martensite s effect in toughness is detrimental ${ }^{82}$. Additionally, the individual strength and hardness of each microstructural constituent influences the toughness properties, where the big mismatch might facilitate the stress concentration. Bainitic ferrite plays an important role during the propagation and growth of a crack. It is capable of arresting / deflecting the cracks in the packet and plate boundaries. Moreover, the ability to resist the propagation of cracks is related to size of the microstructural units. According to Table 4, it is clear that a higher volume fraction of retained austenite solely cannot guarantee an improved toughness as already suggested ${ }^{12}$, and its morphology must also be considered. Results show that the nanostructured bainite obtained at $300{ }^{\circ} \mathrm{C}$ renders lower impact energy comparing to that of samples austempered at $250{ }^{\circ} \mathrm{C}$ despite of its higher volume 
fraction of retained austenite within the microstructure. Similarly, steel 2 possesses a higher impact energy values comparing to that of steel 1 contrary to its lower austenite content at each transformation temperature.

According to the whole performed microstructural characterization, superior impact energy of steel 2 can be explained attending to two facts; first a matrix composed of smaller plates and therefore smaller packets, as it forms from smaller prior austenite grain sizes, and second, a milder matrix in terms of strength. In addition, retained austenite exhibits a smaller size and it is expected to have a smaller mismatch of properties with bainitic ferrite as compared to steel 1 . Different sizes of the fracture facets in Fig. 11 and considerable increment in size of retained austenite films and blocks accompanied by an increment of the $\mathrm{C}$ content when increasing the transformation temperature, Fig. 7 and Table 3, all indicate that higher amount of bigger austenite blocks quickly transform to brittle martensite due to the applied strain during the impact test and, consequently, it cannot play an effective role in blunting the crack tip.

\section{Conclusions}

In this paper, different nanostructured composite like microstructures composed of bainitic ferrite and high carbon retained austenite, obtained by isothermal transformation at low temperatures $\left(200-300^{\circ} \mathrm{C}\right)$ are characterized in two high $\mathrm{C}$ steels considering the microstructure and mechanical properties. High strength with reasonable ductility and impact toughness has been obtained, and such behavior is interpreted in terms of the results of the detailed characterization of the different microstructural features distinguishing this type of microstructures, i.e. phase fraction, chemical composition, size and distribution and dislocation density among others. It has been shown that the Yield and Ultimate Tensile strengths depend on the ratio between the volume fraction of the bainitic ferrite and its plate thickness. Ductility 
on the other hand showed a more complex relation with the amount and mechanical stability of retained austenite, the latter varies with the chemical composition, size and even the strength of the matrix where it is embedded.

Finally, impact toughness is found to also depend on the matrix capability to deflect cracks by means of small bainitic ferrite packet size and plate thicknesses. However there is also the influence of the strength differences between ferrite and austenite, and the composition - size relationship that affect the formation of brittle martensite from retained austenite.

\section{Acknowledgments}

Authors are acknowledging Sahand University of Technology, National Center for Metallurgical Researches (CENIM-CSIC) and Yanshan University for providing the research facilities. CGM and FGC acknowledge the Spanish Ministry of Economy and Competitiveness for the financial support through the contract MAT2013-47460-C5-1-P. 


\section{References}

1. F. G. Caballero, H. Bhadeshia, K. J. A. Mawella, D. G. Jones, and P. Brown: 'Very strong low temperature bainite', Mater. Sci. Technol., 2002, 18(3), 279-284.

2. F. G. Caballero and H. K. D. H. Bhadeshia: 'Very strong bainite', Curr. Opin. Solid State Mater. Sci., 2004, 8(3), 251-257.

3. H. K. D. H. Bhadeshia, P. Brown, and C. Garcia-Mateo: 'Bainite steel and methods of manufacture therof', Patent no. GB2462197, 2010.

4. C. Garcia-Mateo and F. G. Caballero: 'Ultra-high-strength bainitic steels', ISIJ Int, 2005, 45(11), 1736-1740.

5. C. Garcia-Mateo, F. G. Caballero, T. Sourmail, M. Kuntz, J. Cornide, V. Smanio, and R. Elvira: ' Tensile behaviour of a nanocrystalline bainitic steel containing $3 \mathrm{Wt} \%$ silicon', Mater. Sci. Eng., A, 2012, 549, 185-192.

6. C. Garcia-Mateo, T. Sourmail, F. Caballero, V. Smanio, M. Kuntz, C. Ziegler, A. Leiro, E. Vuorinen, R. Elvira, and T. Teeri: ' Nanostructured steel industrialisation: plausible reality', Mater. Sci. Technol., 2014, 30(9), 1071-1078.

7. T. Sourmail, F. Caballero, C. Garcia-Mateo, V. Smanio, C. Ziegler, M. Kuntz, R. Elvira, A. Leiro, E. Vuorinen, and T. Teeri: ' Evaluation of potential of high Si high C steel nanostructured bainite for wear and fatigue applications', Mater. Sci. Technol., 2013, 29(10), 1166-1173.

8. T. Sournmail, V. Smanio, C. Ziegler, V. Heuer, M. Kuntz, F. Caballero, C. Garcia-Mateo, J. Cornide, R. Elvira, A. Leiro, E. Vuorinen, and T. Teeri: 'Novel nanostructured bainitic steel grades to answer the need for high-performance steel components (Nanobain)', European Commission: Luxembourg, 2013, 129.

9. A. Leiro, E. Vuorinen, K. Sundin, B. Prakash, T. Sourmail, V. Smanio, F. Caballero, C. GarciaMateo, and R. Elvira: ' Wear of nano-structured carbide-free bainitic steels under dry rollingsliding conditions' Wear, 2013, 298-299, 42-47.

10. H. Bhadeshia and J. Christian: ' Bainite in steels', Metall. Trans. A, 1990, 21(3), 767-797.

11. H. K. D. H. Bhadeshia: 'Bainite in Steels, 2nd edn.'; 2001, Institute of Materials, London,

12. B. Avishan, S. Yazdani, and S. H. Nedjad: ' Toughness variations in nanostructured bainitic steels', Mater. Sci. Eng., A, 2012, 548, 106- 111.

13. H. K. D. H. Bhadeshia and D. V. Edmonds: Bainite in silicon steels: new composition; property approach Part 1', Met. Sci., 1983, 17(9), 411-419.

14. H. K. D. H. Bhadeshia and D. V. Edmonds: ' Bainite in silicon steels: new composition-property approach Part 2’, Met. Sci., 1983, 17(9), 420-425.

15. G. B. Olson and M. Cohen: ' Kinetics of strain-induced martensitic nucleation', Metall. Mater. Trans. A, 1975, 6(4), 791-795.

16. P. J. Jacques: ' Transformation-induced plasticity for high strength formable steels', Curr. Opin. Solid State Mater. Sci., 2004, 8(3), 259-265.

17. J. A. Jiménez, M. Carsí, O. A. Ruano, and G. Frommeyer: ' Effect of testing temperature and strain rate on the transformation behaviour of retained austenite in low-alloyed multiphase steel', Mater. Sci. Eng., A, 2009, 508(1), 195-199. 
18. O. Matsumura, Y. Sakuma, Y. Ishii, and J. Zhao: 'Effect of retained austenite on formability of high strength sheet steels', ISIJ Int, 1992, 32(10), 1110-1116.

19. G. B. Olson and M. Cohen: ' A mechanism for the strain-induced nucleation of martensitic transformations', J. Less Common Met., 1972, 28(1), 107-118.

20. K. I. Sugimoto, M. Kobayashi, and S. I. Hashimoto: ' Ductility and strain-induced transformation in a high-strength transformation-induced plasticity-aided dual-phase steel', Metall. Mater. Trans. A, 1992, 23(11), 3085-3091.

21. B. Avishan, C. Garcia-Mateo, L. Morales-Rivas, S. Yazdani, and F. G. Caballero: ‘ Strengthening and mechanical stability mechanisms in nanostructured bainite', J. Mater. Sci., 2013, 68, 6121- 6132 .

22. O. Muránsky, P. Lukáš, J. Zrník, and P. Šittner: ' Neutron diffraction analysis of retained austenite stability in Mn-Si steel during plastic deformation', Physica B: Condensed Matter, 2006, 385, 587-589.

23. A. Kammouni, W. Saikaly, M. Dumont, C. Marteau, X. Bano, and A. Charaï: Effect of the bainitic transformation temperature on retained austenite fraction and stability in Ti microalloyed TRIP steels', Mater. Sci. Eng., A, 2009, 518(1), 89-96.

24. T. Furuhara, K. Kikumoto, H. Saito, T. Sekine, T. Ogawa, S. Morito, and T. Maki: ' Phase transformation from fine-grained austenite', ISIJ Int, 2008, 48(8), 1038-1045.

25. K. Sugimoto, K. Nakano, S. Song, and T. Kashima: ' Retained Austenite Characteristics and Stretch-flangeability of High-strength Low-alloy TRIP Type Bainitic Sheet Steels', ISIJ Int, 2002, 42(4), 450-455.

26. C. Garcia-Mateo, F. G. Caballero, J. Chao, C. Capdevila, and C. Garcia de Andres: 'Mechanical stability of retained austenite during plastic deformation of super high strength carbide free bainitic steels' J. Mater. Sci., 2009, 44(17), 4617-4624.

27. J. H. Ryu, D. I. Kim, H. S. Kim, H. K. D. H. Bhadeshia, and D. W. Suh: ' Strain partitioning and mechanical stability of retained austenite', Scr. Mater., 2010, 63(3), 297-299.

28. H. Y. Yu, G. Y. Kai, and M. De Jian: 'Transformation behavior of retained austenite under different deformation modes for low alloyed TRIP-assisted steels', Mater. Sci. Eng., A, 2006, 441(1), 331-335.

29. Y. Sakuma, O. Matsumura, and H. Takechi: 'Mechanical properties and retained austenite in intercritically heat-treated bainite-transformed steel and their variation with $\mathrm{Si}$ and $\mathrm{Mn}$ additions', Metall. Mater. Trans. A, 1991, 22(2), 489-498.

30. W. C. Jeong, D. K. Matlock, and G. Krauss: ' Observation of deformation and transformation behavior of retained austenite in a $0.14 \mathrm{C}-1.2 \mathrm{Si}-1.5 \mathrm{Mn}$ steel with ferrite-bainite-austenite structure', Mater. Sci. Eng., A, 1993, 165(1), 1-8.

31. H. K. D. H. Bhadeshia. 'Materials Algorithms Project', https://www.msm.cam.ac.uk/map/steel/programs/mucg83.html.

32. C. Garcia-Mateo, F. G. Caballero, M. K. Miller, and J. A. Jimenez: ' On measurement of carbon content in retained austenite in a nanostructured bainitic steel', J. Mater. Sci., 2012, 47(2), 10041010 .

33. C. García Mateo, F. G. Caballero, and H. K. D. H. Bhadeshia: ' Acceleration of low-temperature bainite', ISIJ Int, 2003, 43(11), 1821-1825. 
34. C. García Mateo, F. G. Caballero, and H. K. D. H. Bhadeshia: 'Development of hard bainite', ISIJ Int, 2003, 43(8), 1238-1243.

35. C. Garcia-Mateo and F. G. Caballero: ' Design of carbide-free low-temperature ultra high strength bainitic steels', Int. J. Mater. Res., 2007, 98(2), 137-143.

36. C. García de Andrés, M. J. Bartolomé, C. Capdevila, D. San Martın, F. G. Caballero, and V. López: ' Metallographic techniques for the determination of the austenite grain size in mediumcarbon microalloyed steels', Mater. Charact., 2001, 46(5), 389-398.

37. C. García de Andrés, F. G. Caballero, C. Capdevila, and D. San Martín: ' Revealing austenite grain boundaries by thermal etching: advantages and disadvantages', Mater. Charact., 2002, 49(2), 121-127.

38. L. C. Chang and H. K. D. H. Bhadeshia: ' Austenite films in bainitic microstructures', Mater. Sci. Technol., 1995, 11(9), 874-881.

39. M. J. Dickson: ' The significance of texture parameters in phase analysis by X-ray diffraction', $J$ Appl. Crystallogr., 1969, 2(4), 176-180.

40. H. M. Rietveld: ' A profile refinement method for nuclear and magnetic structures', $J$ Appl. Crystallogr., 1969, 2(2), 65-71.

41. D. J. Dyson and B. Holmes: 'Effect of alloying additions on the lattice parameter of austenite', $J$. Iron Steel Inst, 1970, 208(5), 469-474.

42. G. K. Williamson and R. E. Smallman: ' Dislocation densities in some annealed and cold-worked metals from measurements on the X-ray debye-scherrer spectrum', Philos. Mag., 1956, 1(1), 3446.

43. G. K. Williamson and W. H. Hall: ' X-ray line broadening from filed aluminium and wolfram', Acta Metall., 1953, 1(1), 22-31.

44. MTDATA, Phase Diagrame Software, 2004: National Physical Laboratory Teddington, UK.

45. M. Y. Sherif, C. G. Mateo, T. Sourmail, and H. Bhadeshia: ' Stability of retained austenite in TRIP-assisted steels', Mater. Sci. Technol., 2004, 20(3), 319-322.

46. F. G. Caballero, H. W. Yen, M. K. Miller, J. R. Yang, J. Cornide, and C. Garcia-Mateo: ‘ Complementary use of transmission electron microscopy and atom probe tomography for the examination of plastic accommodation in nanocrystalline bainitic steels', Acta Mater., 2011, 59(15), 6117-6123.

47. F. G. Caballero, M. K. Miller, S. S. Babu, and C. García-Mateo: ‘ Atomic scale observations of bainite transformation in a high carbon high silicon steel', Acta Mater., 2007, 55(1), 381-390.

48. F. G. Caballero, M. K. Miller, C. Garcia-Mateo, C. Capdevila, and S. S. Babu: ' Redistribution of alloying elements during tempering of a nanocrystalline steel', Acta Mater., 2008, 56(2), 188199.

49. F. G. Caballero, M. K. Miller, and C. Garcia-Mateo: ' Atom Probe Tomography Analysis of Precipitation during Tempering of a Nanostructured Bainitic Steel', Metall. Mater. Trans. A, 2011, 42(12), 3660-3668.

50. C. Garcia-Mateo, F. G. Caballero, C. Capdevila, and C. Andres: 'Estimation of dislocation density in bainitic microstructures using high-resolution dilatometry', Scr. Mater., 2009, 61(9), 855-858. 
51. J. Cornide, G. Miyamoto, F. G. Caballero, T. Furuhara, M. K. Miller, and C. García-Mateo: ‘ Distribution of dislocations in nanostructured bainite', Solid State Phenom., 2011, 172, 117-122.

52. H. K. D. H. Bhadeshia and D. V. Edmonds: ' The bainite transformation in a silicon steel', Metall. Mater. Trans. A, 1979, 10(7), 895-907.

53. L. Chang and H. Bhadeshia: ' Metallographic observations of bainite transformation mechanism', Mater. Sci. Technol., 1995, 11(2), 105-108.

54. B. Avishan, C. Garcia-Mateo, S. Yazdani, and F. G. Caballero: 'Retained austenite thermal stability in a nanostructured bainitic steel', Mater. Charact., 2013, 81, 105- 110.

55. G. Smith: 'the microstructure and yielding behaviour of some Ti steels 'University of Cambridge.

56. H. Stone, M. Peet, H. Bhadeshia, P. Withers, S. S. Babu, and E. D. Specht: 'Synchrotron X-ray studies of austenite and bainitic ferrite', Proceedings of the Royal Society A: Mathematical, Physical and Engineering Science, 2008, 464(2092), 1009-1027.

57. H. Bhadeshia and D. Edmonds: ' The mechanism of bainite formation in steels', Acta Metall., 1980, 28(9), 1265-1273.

58. T. Furuhara, H. Kawata, S. Morito, and T. Maki: 'Crystallography of upper bainite in Fe-Ni-C alloys', Mater. Sci. Eng., A, 2006, 431(1), 228-236.

59. S. B. Singh and H. K. D. H. Bhadeshia: 'Estimation of bainite plate-thickness in low-alloy steels', Mater. Sci. Eng., A, 1998, 245(1), 72-79.

60. J. Cornide, C. Garcia-Mateo, C. Capdevila, and F. G. Caballero: 'An Assessment of the Contributing Factors to the Nanoscale Structural Refinement of Advanced Bainitic Steels', $J$. Alloys Compd., 2013, 43- 47.

61. H. K. D. H. Bhadeshia and R. W. K. Honeycombe, Steel, Microstructure and properties. 2006, Butterworths-Heinemann (Elsevier)

62. S. Zajac, J. Komenda, P. Morris, P. Dierickx, S. Matera, and F. Penalba Diaz: 'Quantitative structure-property relationships for complex bainitic microstructures', 2005, European Commission, Luxembourg. p. 157.

63. A. Matsuzaki and H. Bhadeshia: 'Effect of austenite grain size and bainite morphology on overall kinetics of bainite transformation in steels', Mater. Sci. Technol., 1999, 15(5), 518-522.

64. F. G. Caballero, M. K. Miller, C. Garcia-Mateo, J. Cornide, and M. J. Santofimia: ‘ Temperature Dependence of Carbon Supersaturation of Ferrite In Bainitic Steels', Scr. Mater., 2012, 67(10), 846-849.

65. F. Caballero, M. Miller, C. Garcia-Mateo, and J. Cornide: ' New experimental evidence of the diffusionless transformation nature of bainite', J. Alloys Compd., 2013, 577, 626- 630.

66. C. Hulme-Smith, I. Lonardelli, A. Dippel, and H. Bhadeshia: ' Experimental evidence for noncubic bainitic ferrite', Scr. Mater., 2013, 69(5), 409-412.

67. J. H. Jang, H. Bhadeshia, and D.-W. Suh: ' Solubility of carbon in tetragonal ferrite in equilibrium with austenite', Scr. Mater., 2013, 68(3), 195-198.

68. G. Langford and M. Cohen: ' Calculation of cell-size strengthening of wire-drawn iron', Metall. Mater. Trans. B, 1970, 1(5), 1478-1480. 
69. G. Langford and M. Cohen: 'Strain hardening of iron by severe plastic deformation', ASM Trans Quart, 1969, 62(3), 623-638.

70. K. Nohara: ' Composition and Grain Size Dependence of Strain-Induced Martensitic Transformation in Metastable Stainless Steel', J. Iron Steel Inst., 1977, 63(5), 772-780.

71. L. Samek, E. De Moor, J. Penning, and B. C. De Cooman: ' Influence of alloying elements on the kinetics of strain-induced martensitic nucleation in low-alloy, multiphase high-strength steels', Metall. Mater. Trans. A, 2006, 37(1), 109-124.

72. A. Z. Hanzaki, P. Hodgson, and S. Yue: ' Retained austenite characteristics in thermomechanically processed Si-Mn transformation-induced plasticity steels', Metall. Mater. Trans. A, 1997, 28(11), 2405-2414.

73. J. Wang and S. Van Der Zwaag: 'Stabilization mechanisms of retained austenite in transformation-induced plasticity steel', Metall. Mater. Trans. A, 2001, 32(6), 1527-1539.

74. C. A. N. Lanzillotto and F. B. Pickering: ' Structure-property relationships in dual-phase steels', Met. Sci., 1982, 16(8), 371-382.

75. N. K. Balliger and T. Gladman: 'Work hardening of dual-phase steels', Met. Sci., 1981, 15(3), 95-108.

76. S. Zhang and K. Findley: ' Quantitative assessment of the effects of microstructure on the stability of retained austenite in TRIP steels', Acta mater, 2013, 61(6), 1895-1903.

77. P. Jacques, F. Delannay, and J. Ladrière: ' On the influence of interactions between phases on the mechanical stability of retained austenite in transformation-induced plasticity multiphase steels', Metall. Mater. Trans. A, 2001, 32(11), 2759-2768.

78. S. Babu, S. Vogel, C. Garcia-Mateo, B. Clausen, L. Morales-Rivas, and F. Caballero: ‘ Microstructure evolution during tensile deformation of a nanostructured bainitic steel', Scripta Mater, 2013, 69(11), 777-780.

79. C. Herrera, D. Ponge, and D. Raabe: ' Design of a novel Mn-based 1GPa duplex stainless TRIP steel with $60 \%$ ductility by a reduction of austenite stability', Acta Mater., 2011, 59(11), 46534664.

80. M. peet: 'Modelling the Hot-Deformation of Austenite'; 2001, University of Cambridge,

81. R. Wu, W. Li, S. Zhou, Y. Zhong, L. Wang, and X. Jin: ' Effect of Retained Austenite on the Fracture Toughness of Quenching and Partitioning (Q\&P)-Treated Sheet Steels', Metall. Mater. Trans. A, 2014, 45(4), 1892-1902.

82. S. Chatterjee and H. Bhadeshia: ' TRIP-assisted steels: cracking of high-carbon martensite', Mater. Sci. Technol., 2006, 22(6), 645-649. 


\section{Figure captions:}

Fig. 1. XRD profile for steel 1 and steel 2 at the end of bainitic heat treatment at each transformation temperature.

Fig. 2. FEG- SEM pictures of steel 1 a, c, e and steel 2 b, d, f at 200,250 and $300{ }^{\circ} \mathrm{C}$, at the end of the bainitic transformation, respectively.

Fig. 3. TEM pictures of steel $1 \mathrm{a}$, c, e and steel $2 \mathrm{~b}, \mathrm{~d}, \mathrm{f}$ at 200,250 and $300{ }^{\circ} \mathrm{C}$, at the end of the bainitic transformation, respectively.

Fig. 4. An example of the transformation twins in blocky austenite in steel 1 at $250{ }^{\circ} \mathrm{C}$.

Fig. 5. Measured apparent thickness distribution of bainitic ferrite plates for both steels after transformation at a) $200{ }^{\circ} \mathrm{C}$, b) $250{ }^{\circ} \mathrm{C}$ and c) $300^{\circ} \mathrm{C}$

Fig. 6. Measured apparent thickness distribution of thin films of retained austenite for both steels after transformation at a) $200{ }^{\circ} \mathrm{C}$, b) $250{ }^{\circ} \mathrm{C}$ and c) $300{ }^{\circ} \mathrm{C}$.

Fig. 7. Measured apparent size distribution of retained austenite blocks for both steels after transformation at a) $200{ }^{\circ} \mathrm{C}$, b) $250{ }^{\circ} \mathrm{C}$ and c) $300^{\circ} \mathrm{C}$.

Fig. 8. Typical engineering stress- engineering strain curves attained at room temperature for each steels obtained at each transformation temperatures.

Fig. 9. Variation of a) Ys and UTS with $V \alpha_{b} / t \alpha_{b}$ and $b$ ) elongation with stability factor.

Fig. 10. Variation of the incremental work-hardening exponent, $n$, with true strain for samples austempered at a) 200 , b) 250 and c) $300{ }^{\circ} \mathrm{C}$, Dashed line represents the instability criterion, i.e., $\varepsilon_{\mathrm{p}}=\mathrm{n}$.

Fig. 11. Fracture surfaces of impact test samples for steel $1 \mathrm{a}$ and $\mathrm{b}$ and steel $2 \mathrm{c}$ and $\mathrm{d}$. a and $\mathrm{c}$ austempered at $250{ }^{\circ} \mathrm{C}$ and $\mathrm{b}$ and $\mathrm{d}$ austempered at $300{ }^{\circ} \mathrm{C}$. 


\section{Table captions:}

Table 1- Chemical composition of cast alloys (wt.\%).

Table 2 - Quantitative characterization data for the microstructures after isothermal treatment at different temperatures where $V \alpha_{b}, V \gamma_{f}$ and $V \gamma_{b}$ represent the volume fraction of bainitic ferrite, and retained austenite films and blocks, respectively. $\mathrm{C} \gamma$ is the austenite carbon content and $\rho_{\gamma}$ and $\rho_{\alpha}$ are the dislocation densities in austenite and bainitic ferrite.

Table 3- Quantitative data on the scale of the microstructure attained after different heat treatment conditions, where $\mathrm{t}$ stands for the apparent plate thickness $(\mathrm{nm})$ of the indicated phases and morphologies.

Table 4- Quantitative mechanical properties data derived from engineering stress - engineering strain curves of shown in Fig. 8 and impact test results obtained at room temperature. 


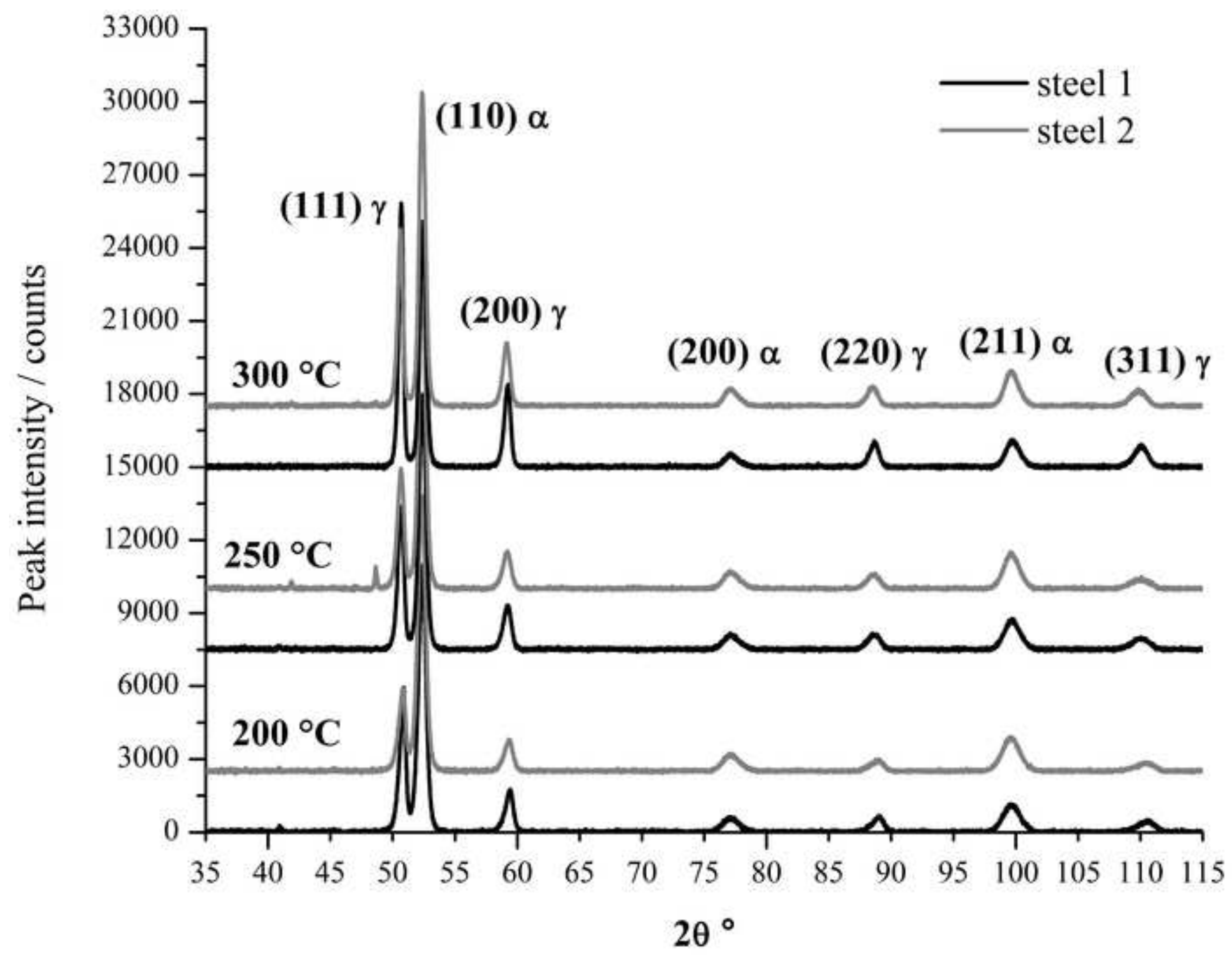




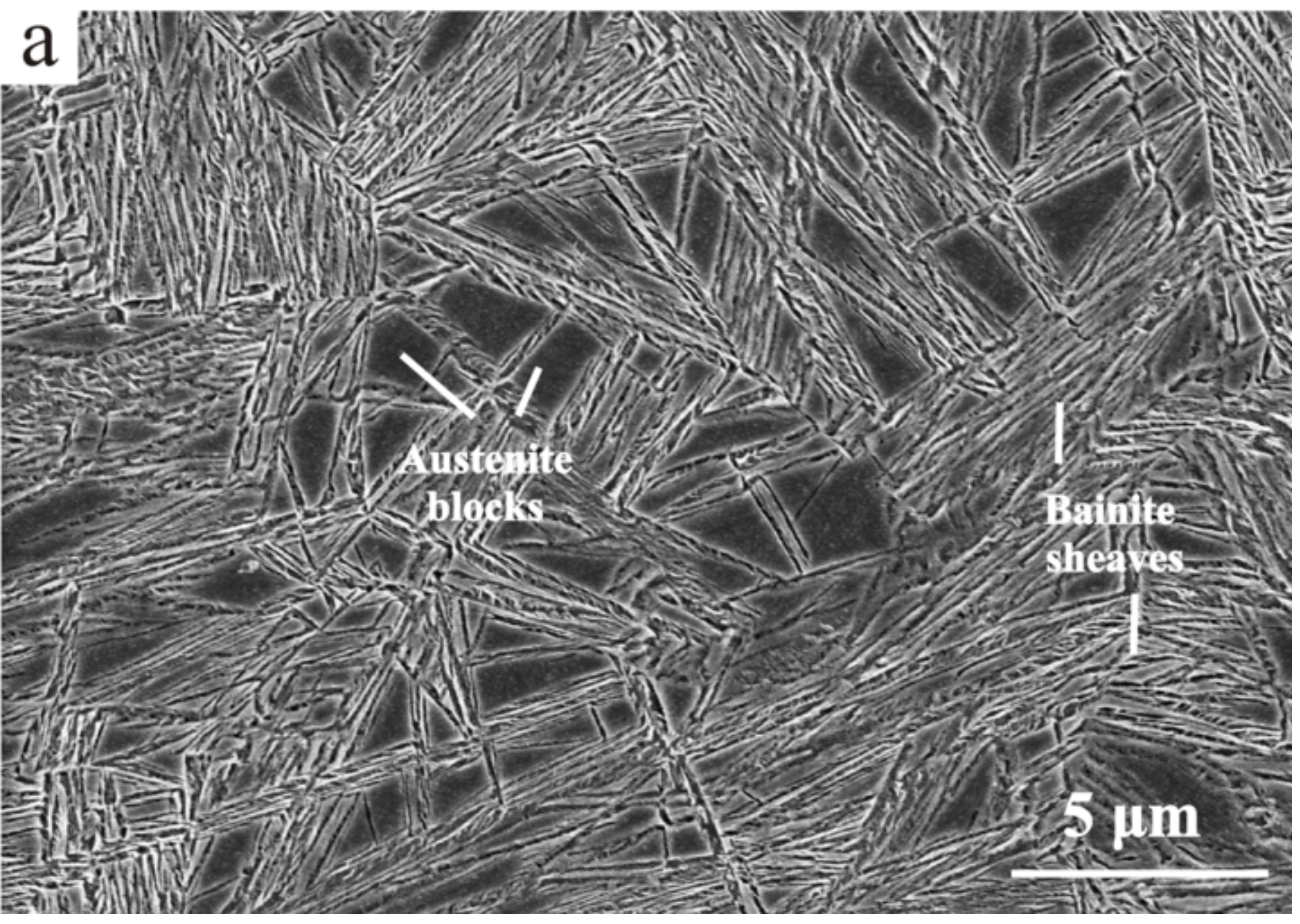




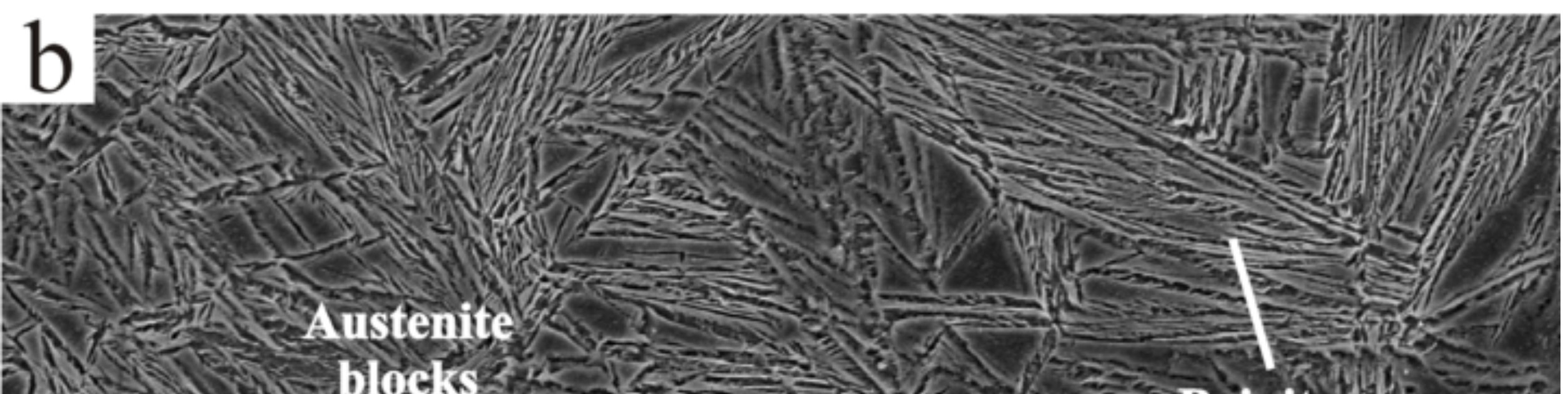

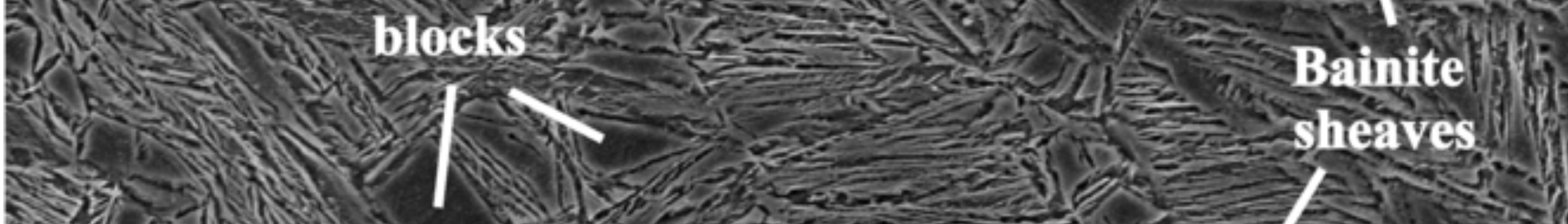

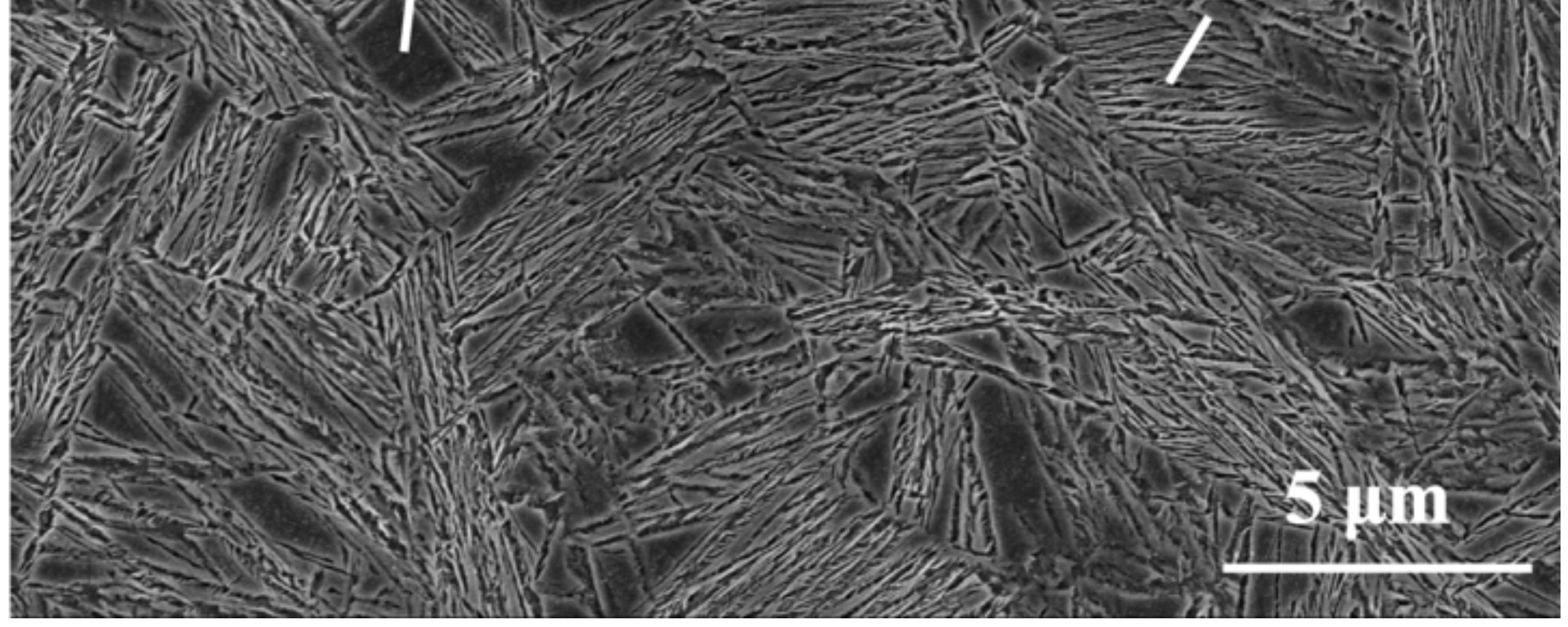




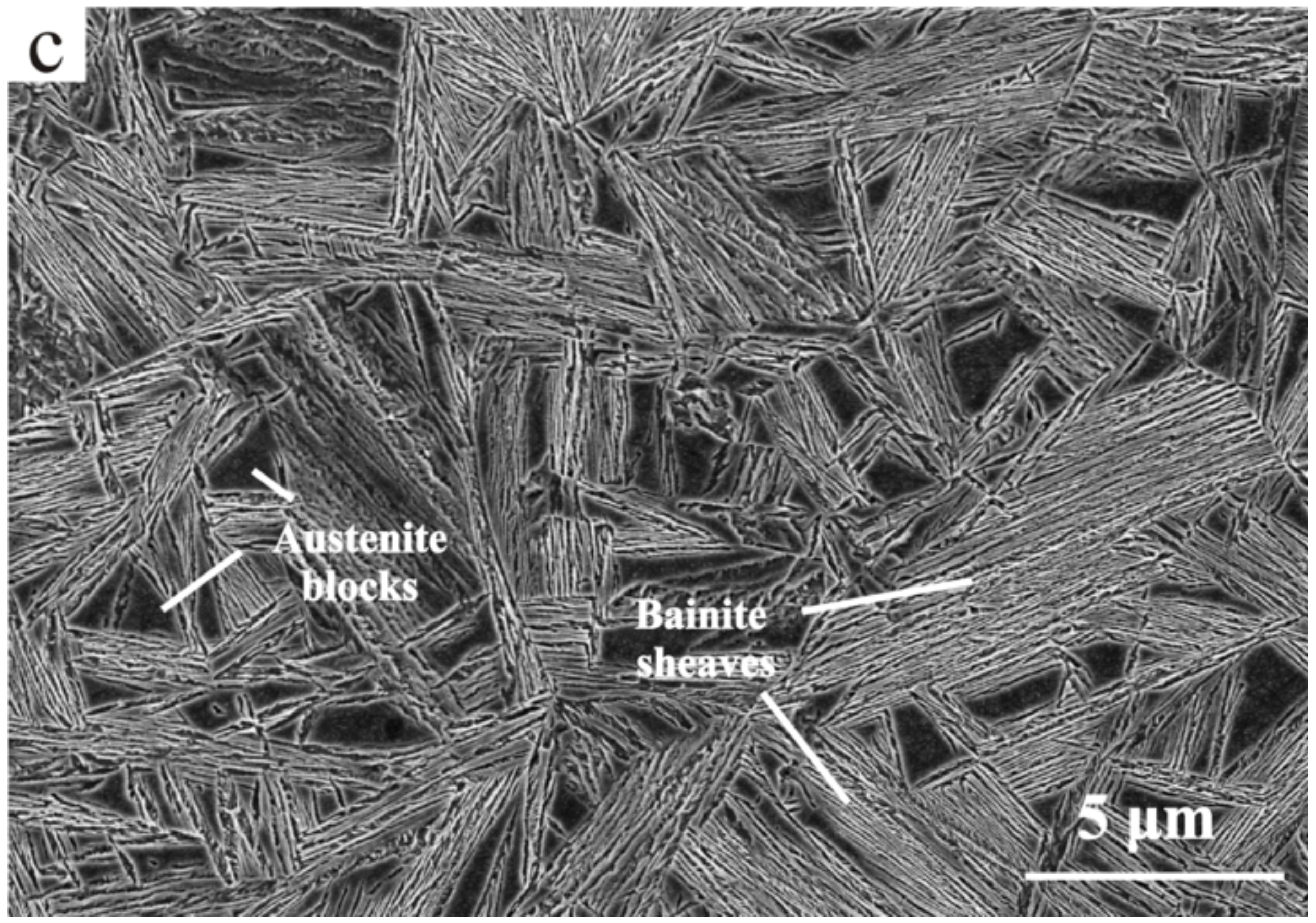




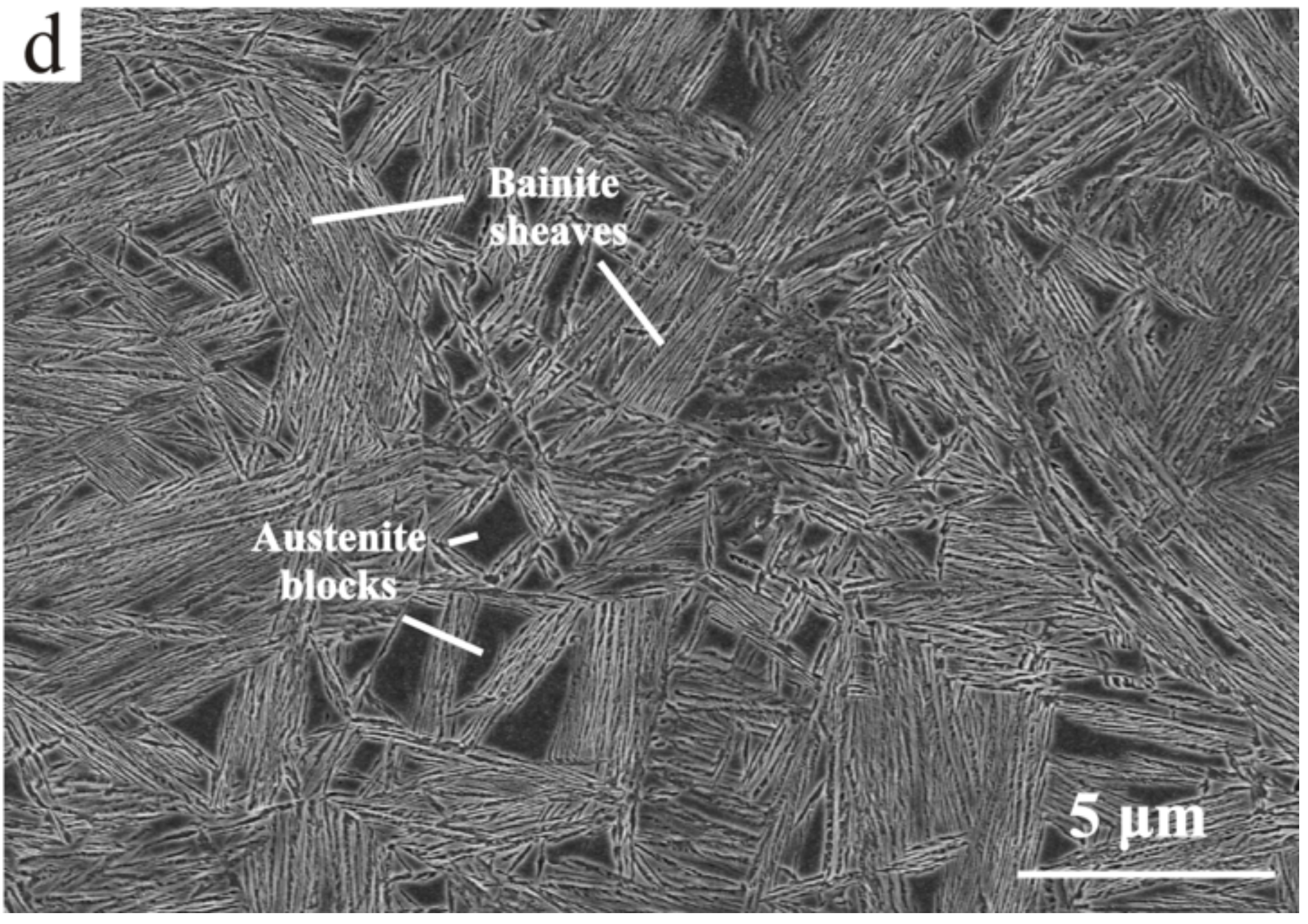




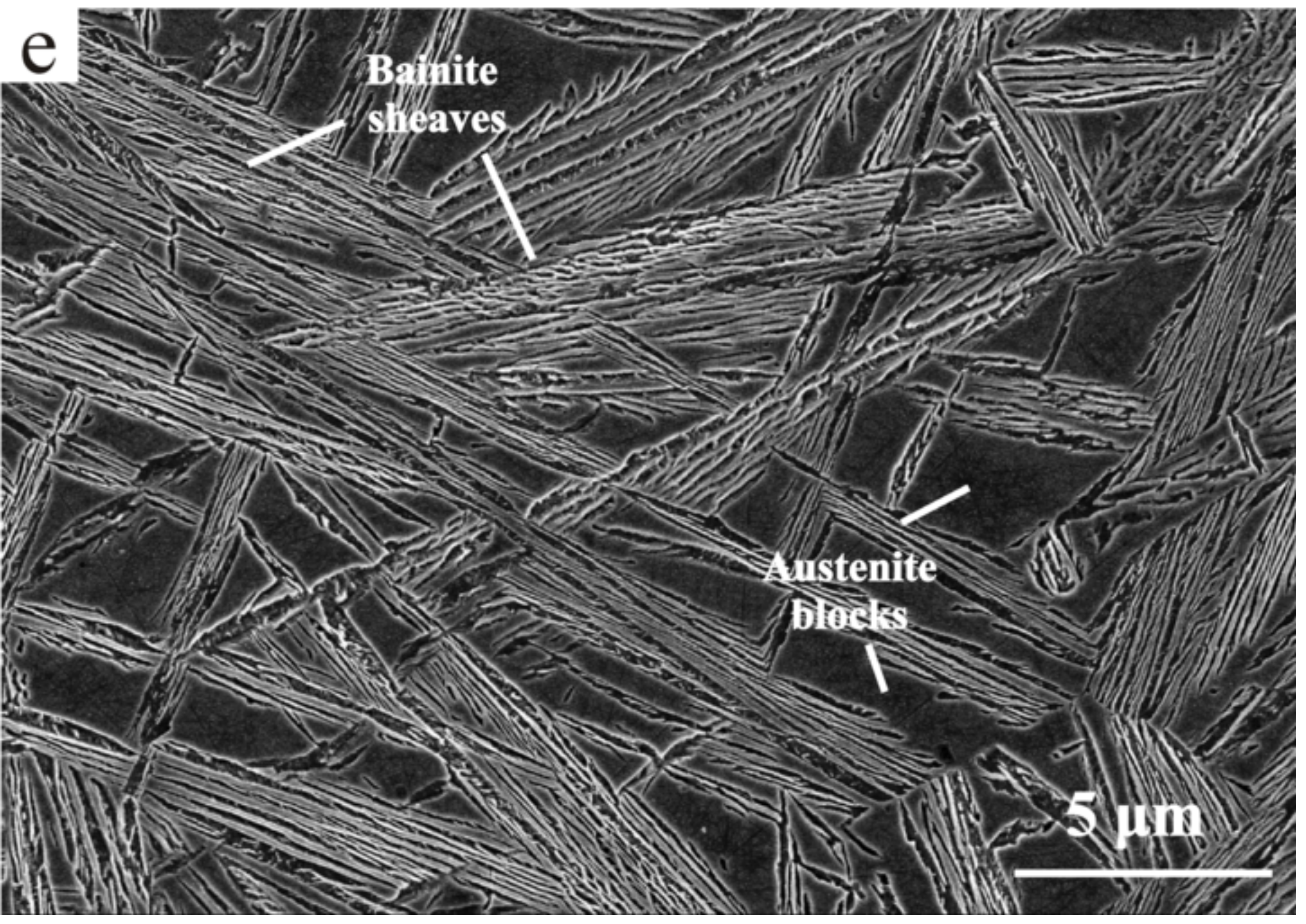




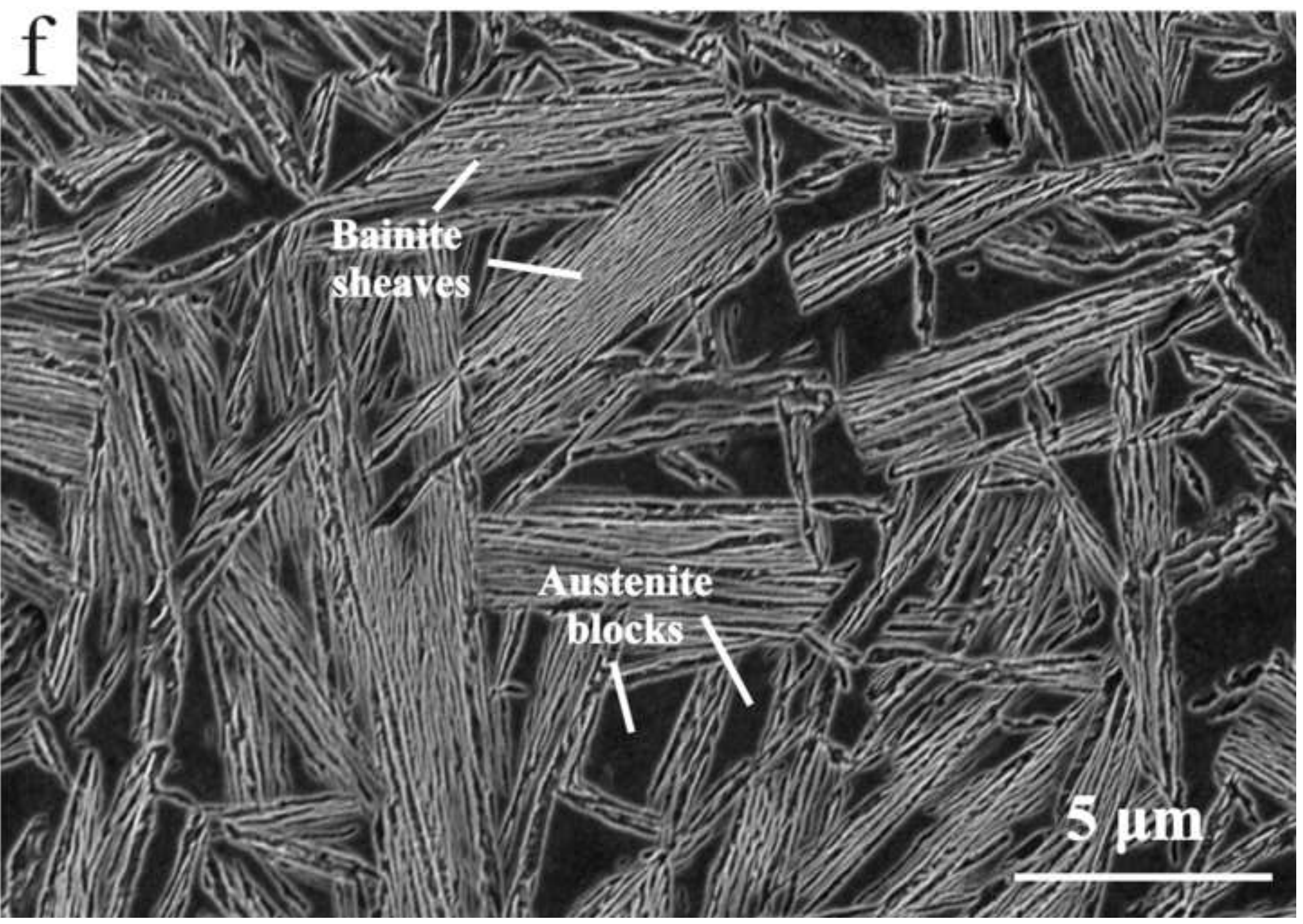




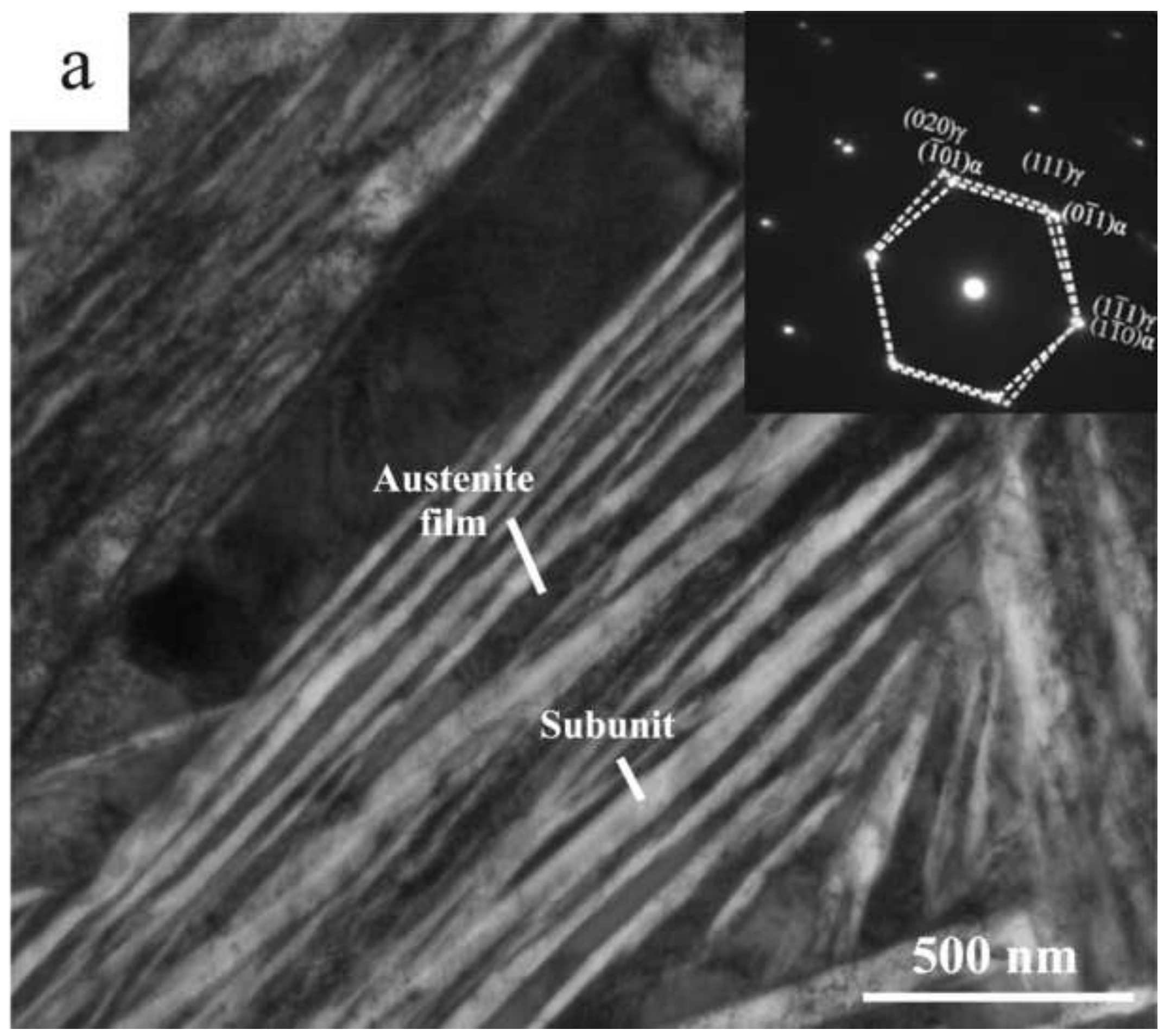




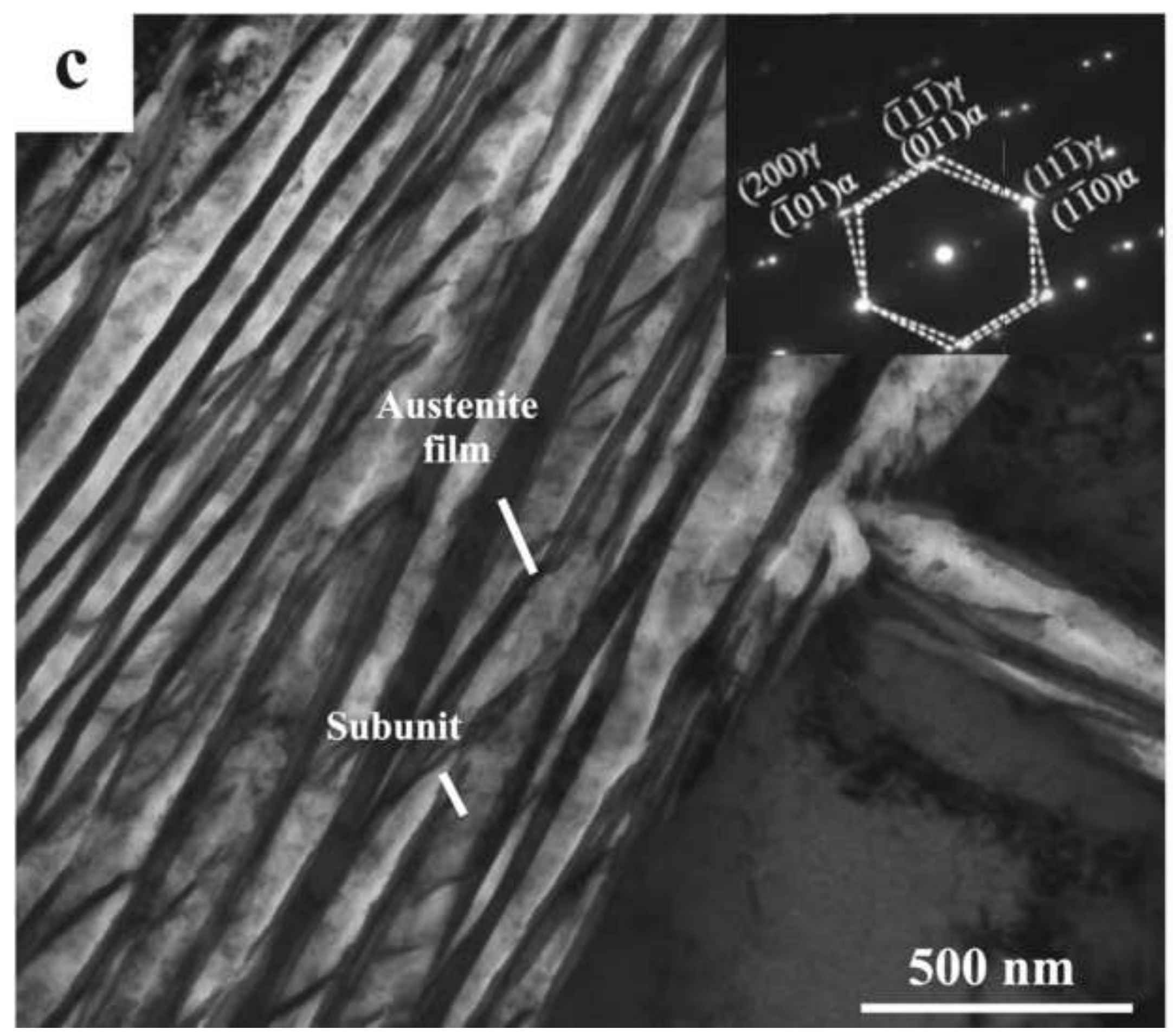




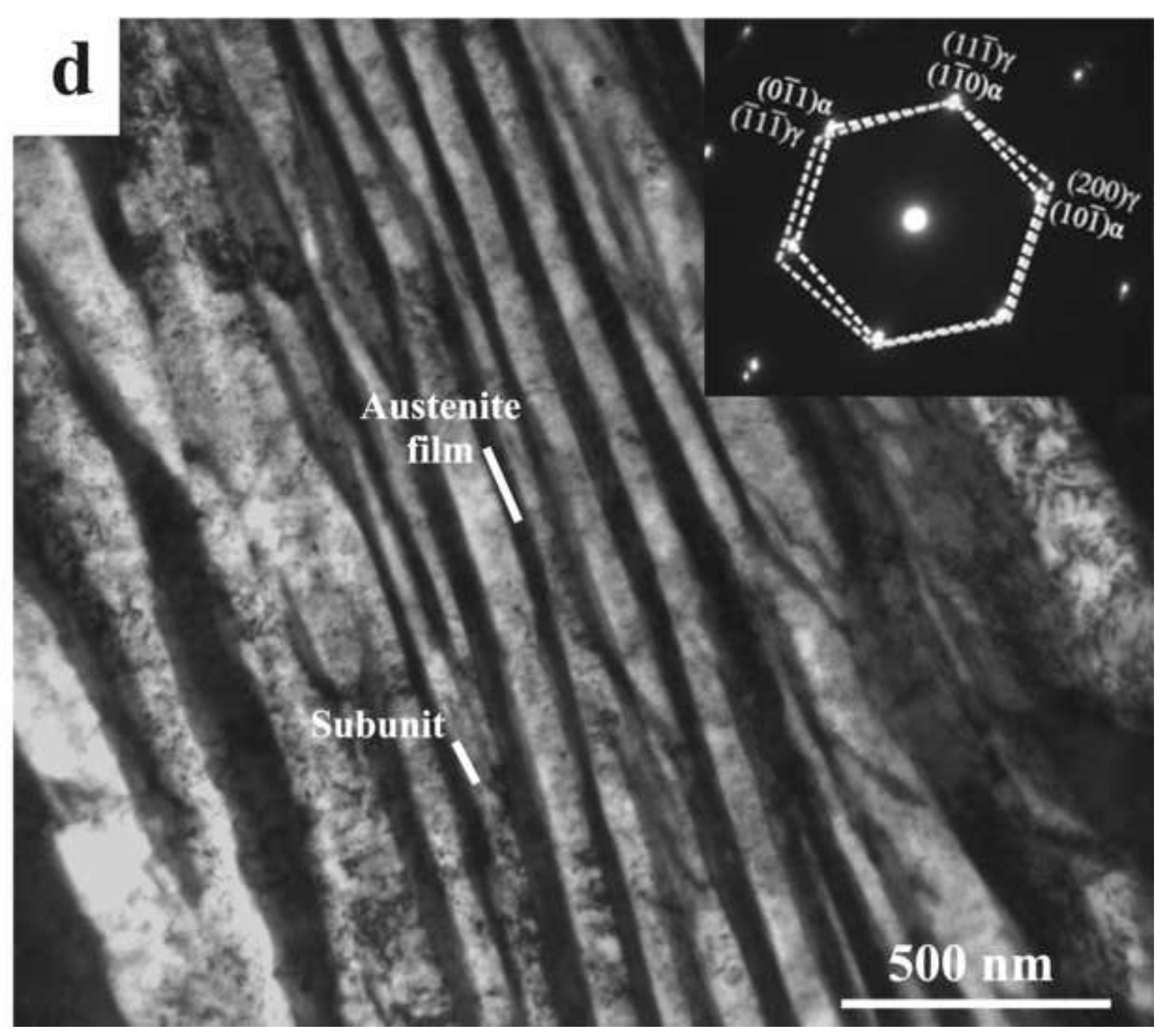




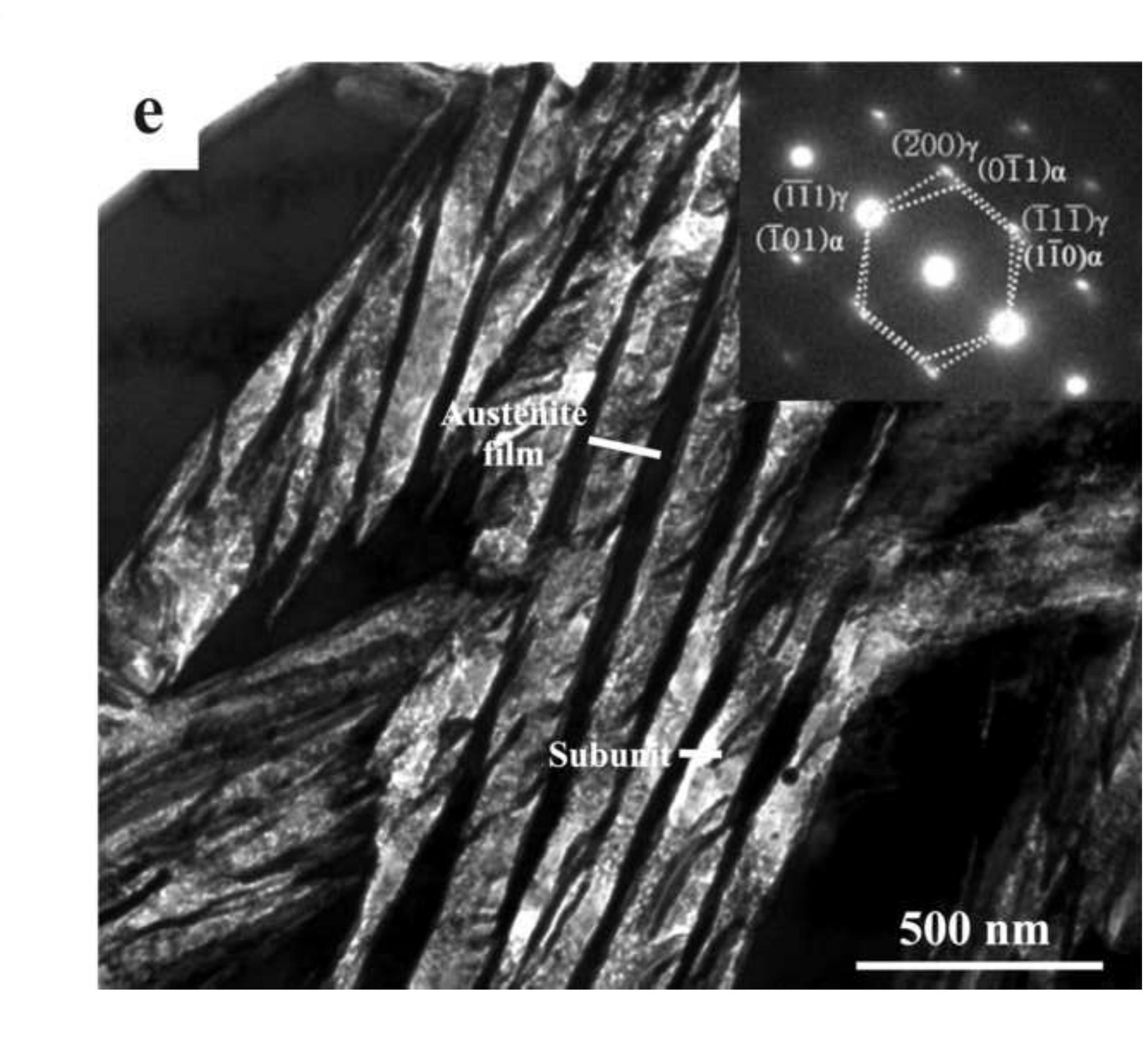

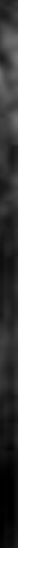
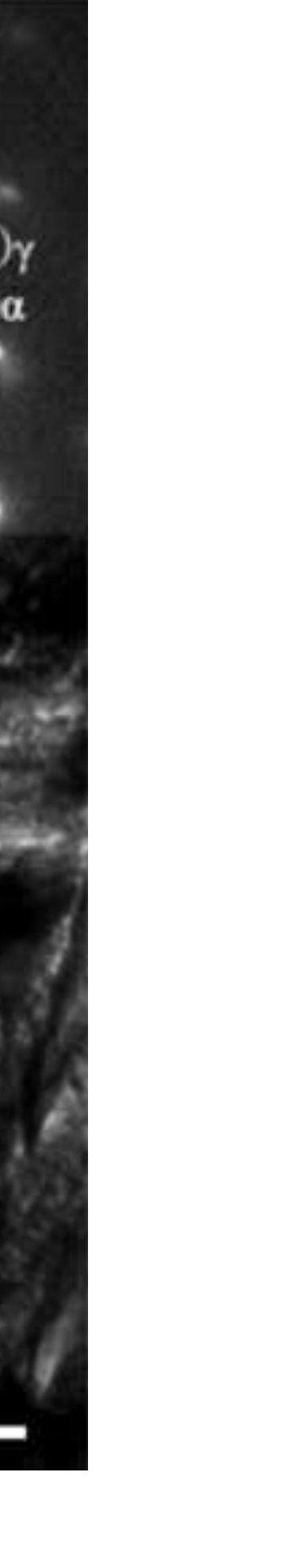

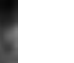$$
\text { . }
$$

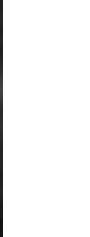

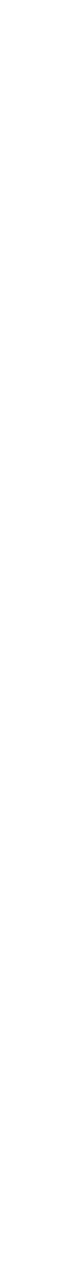
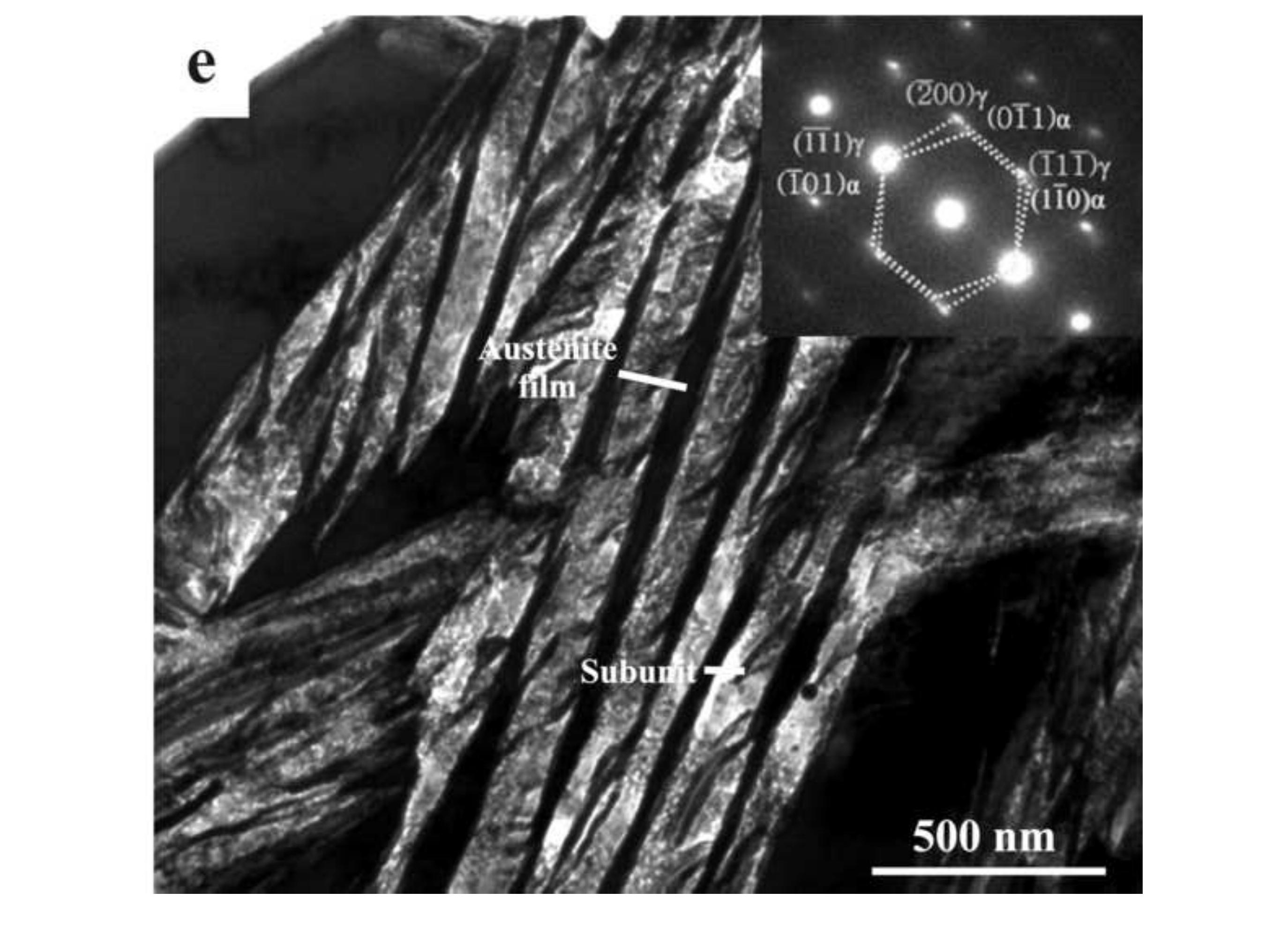

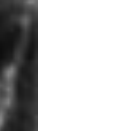
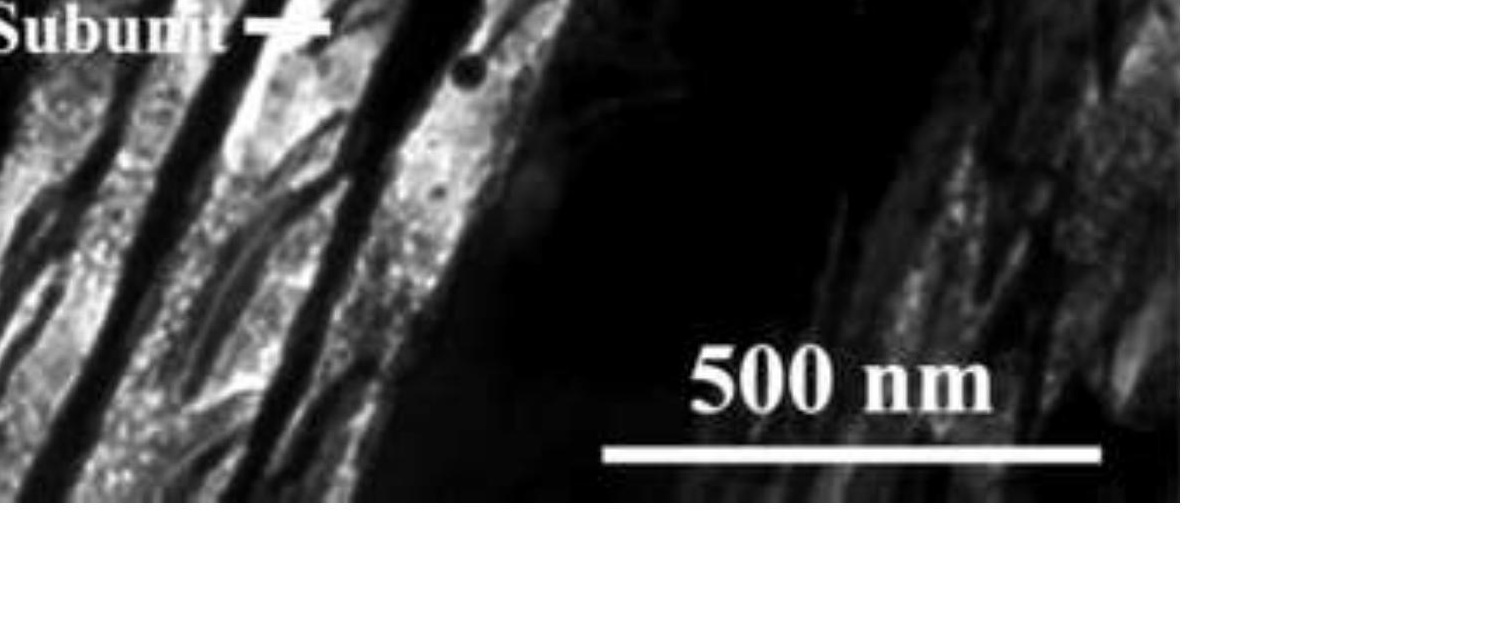


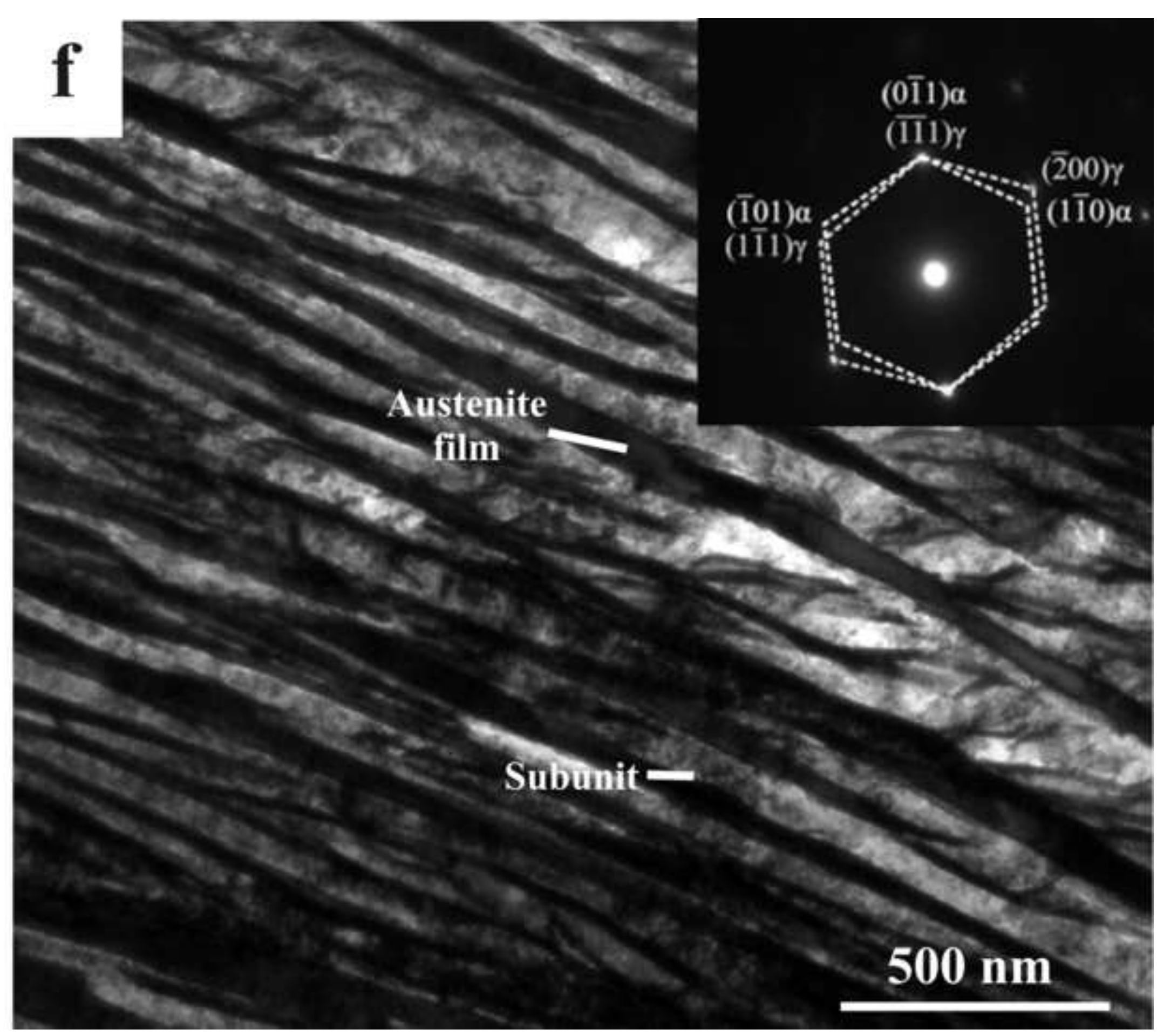




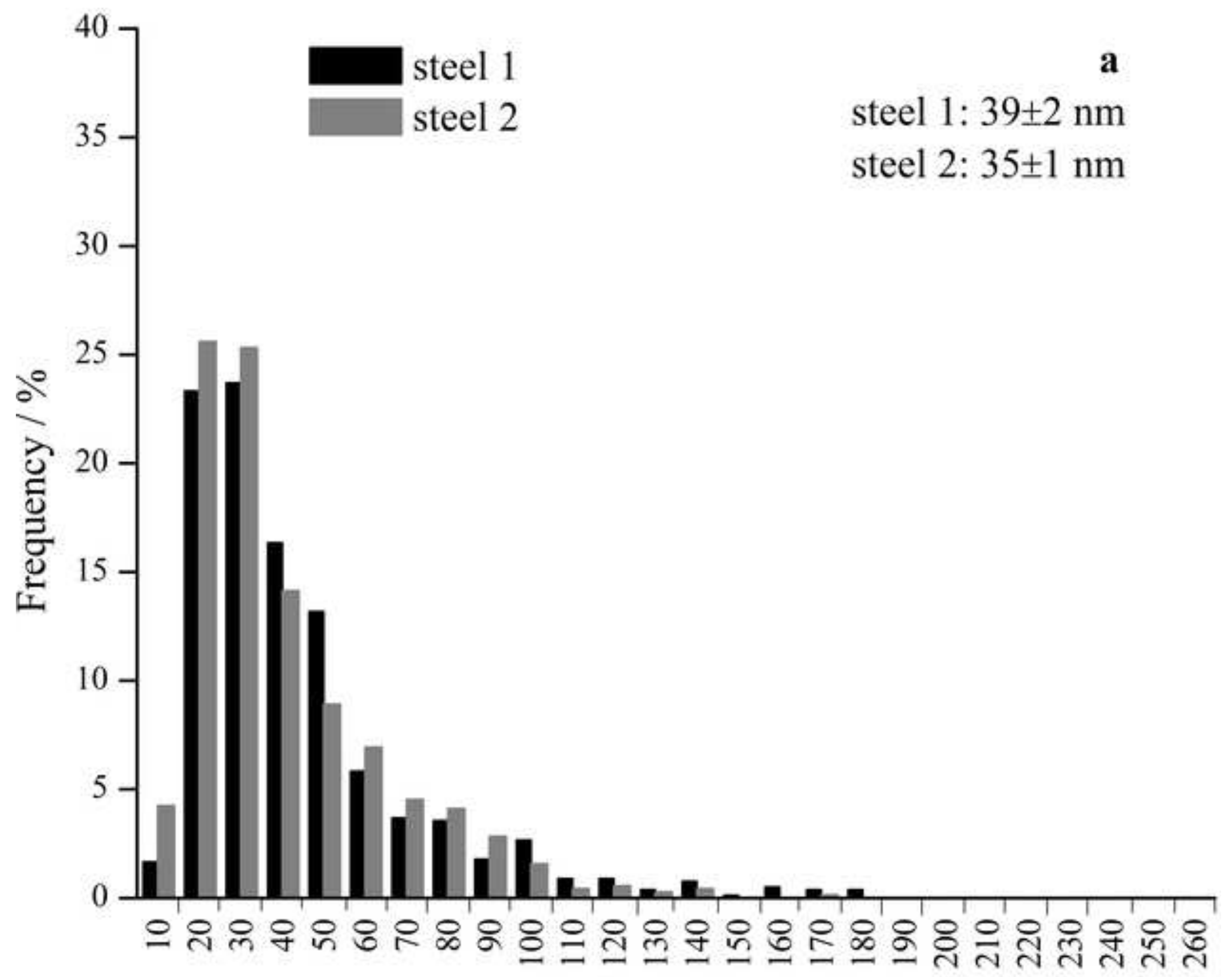

Bainitic ferrite plate thickness / nm 


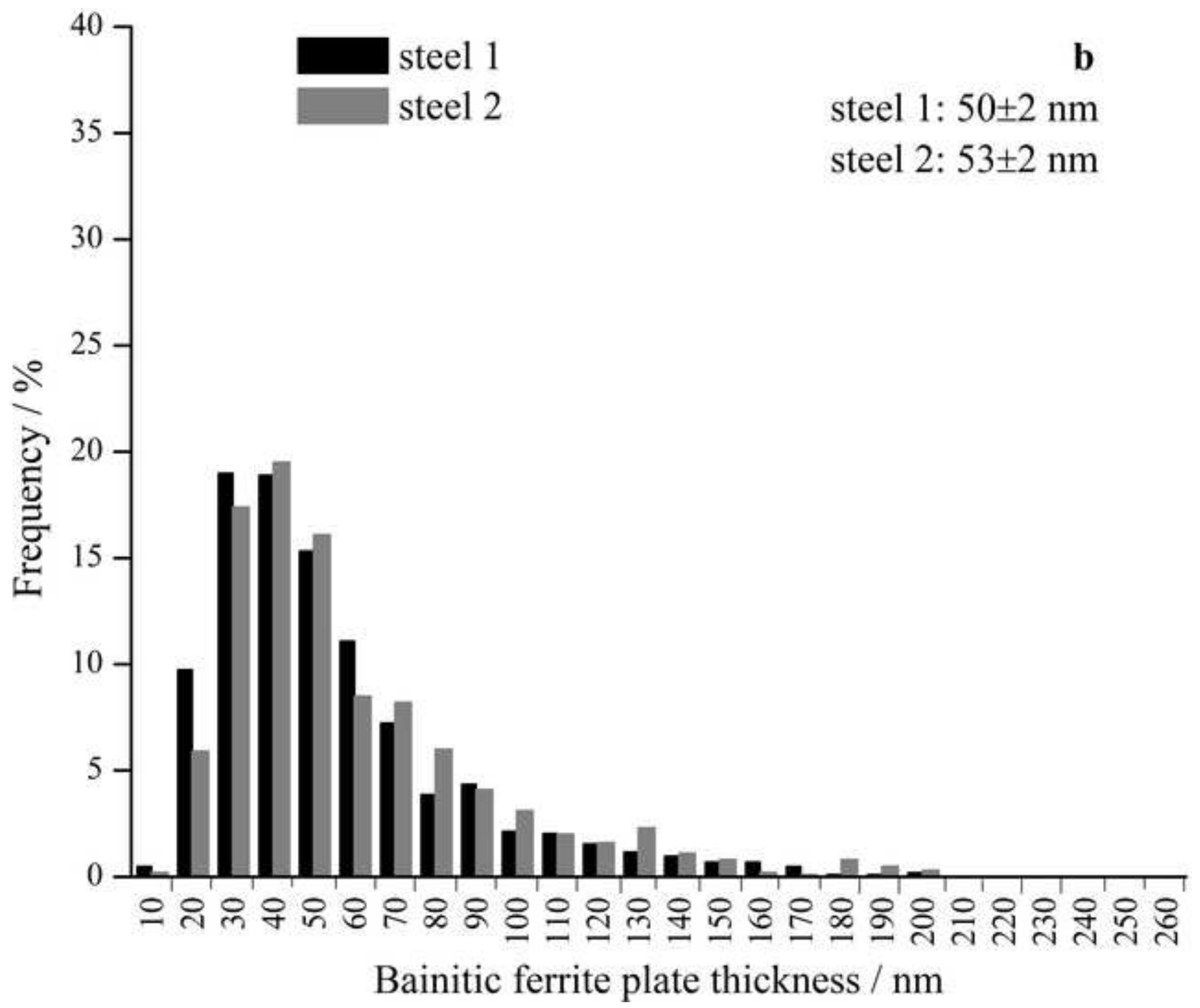




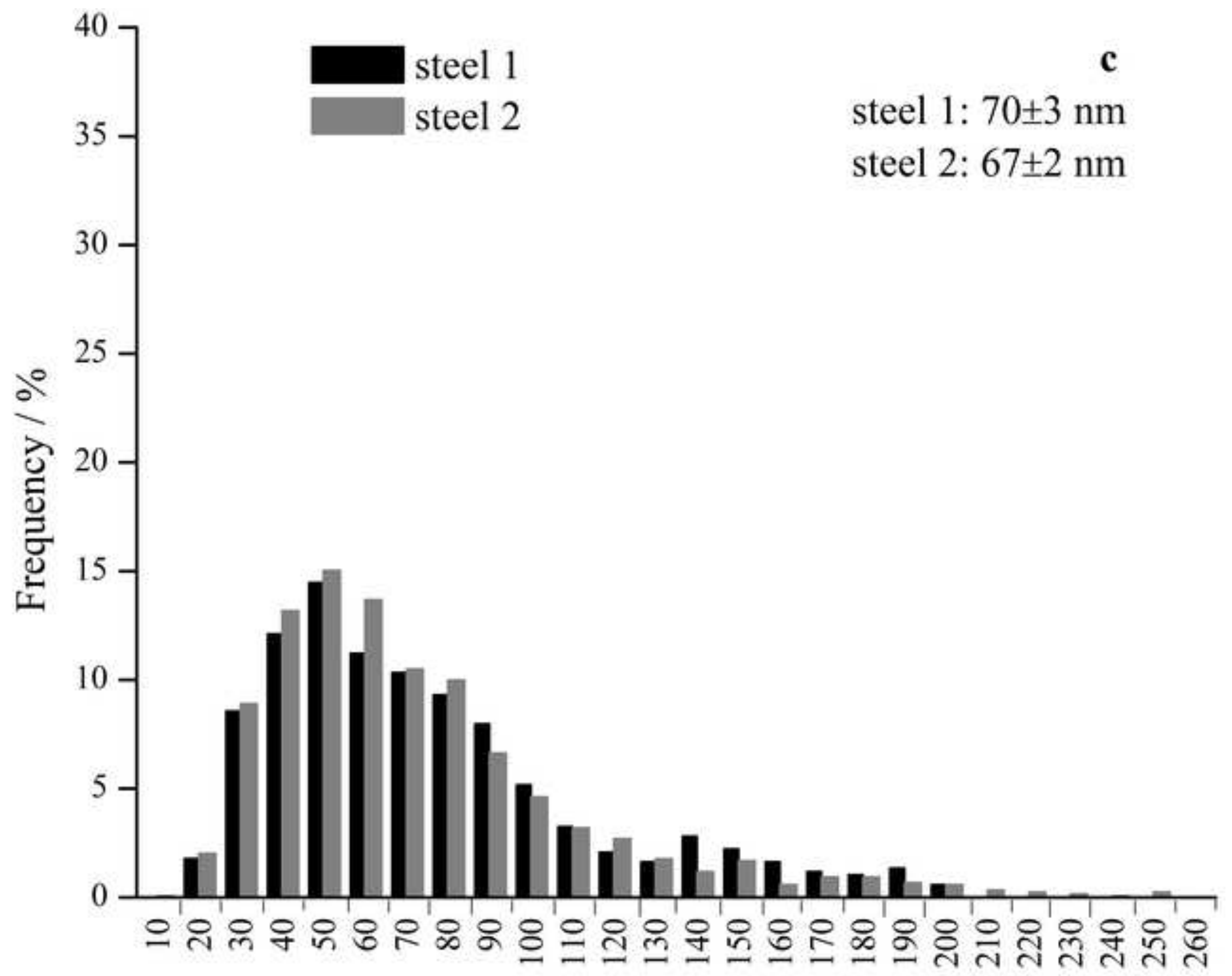

Bainitic ferrite plate thickness / nm 


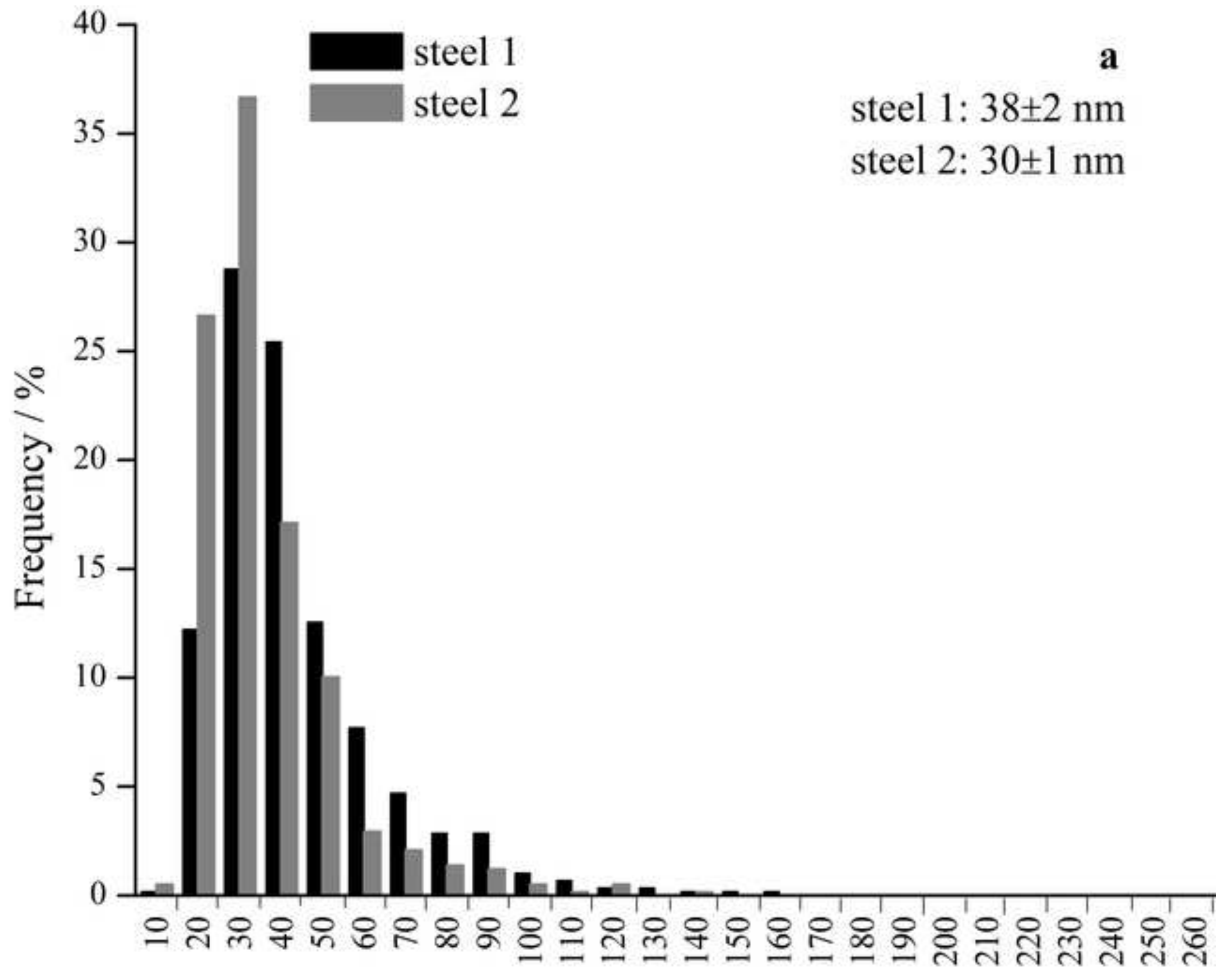

Austenite film thickness / nm 


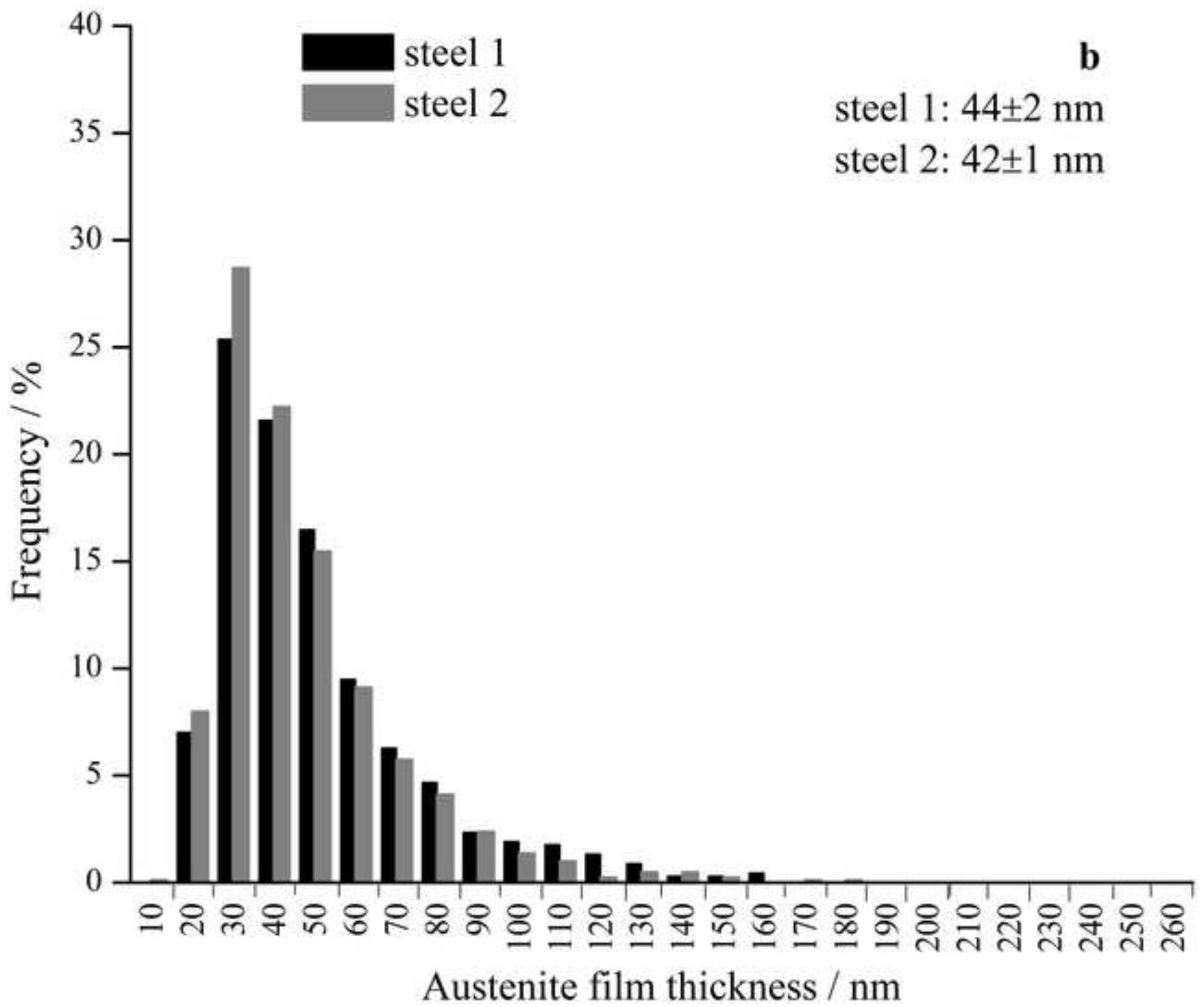




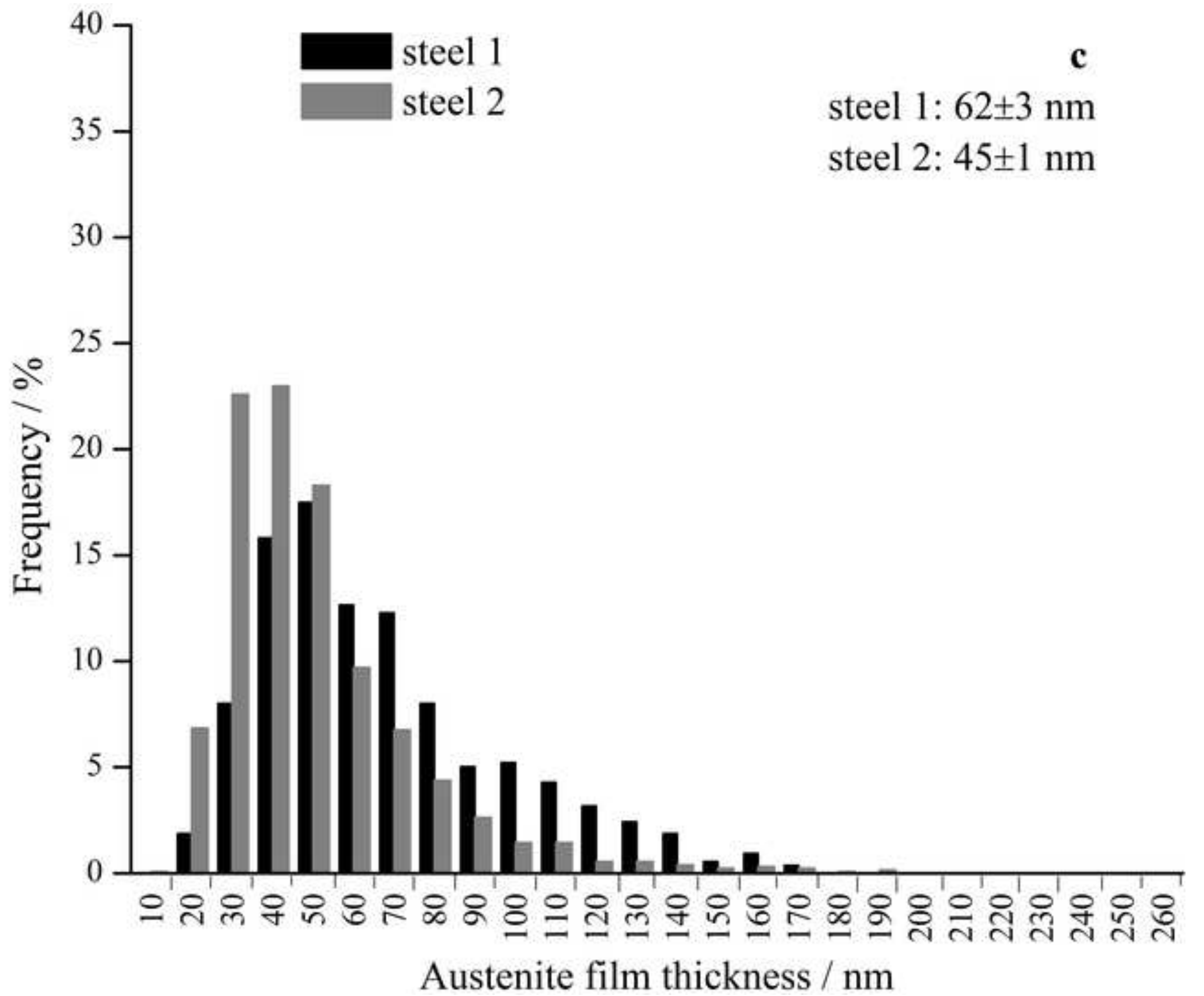




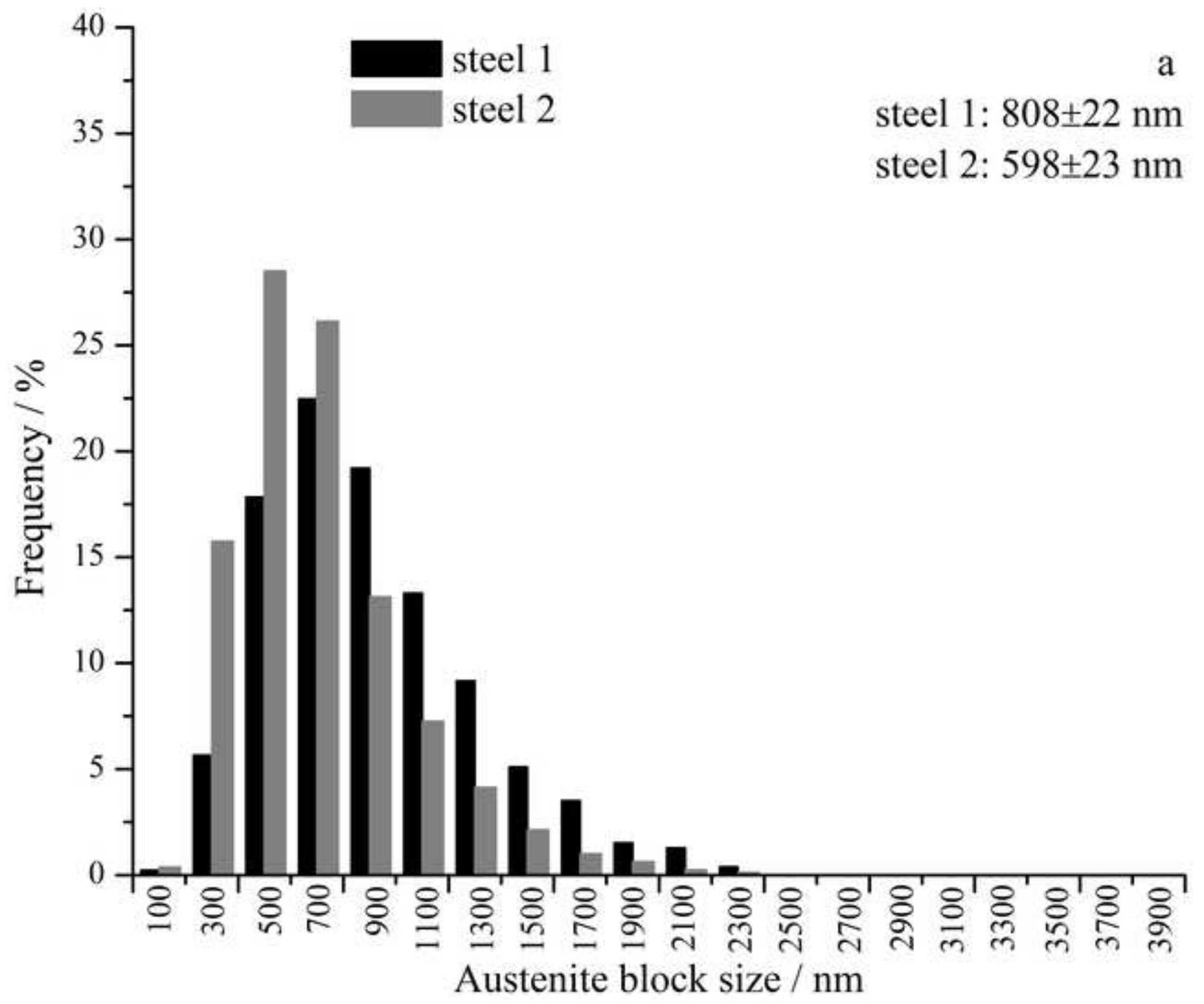




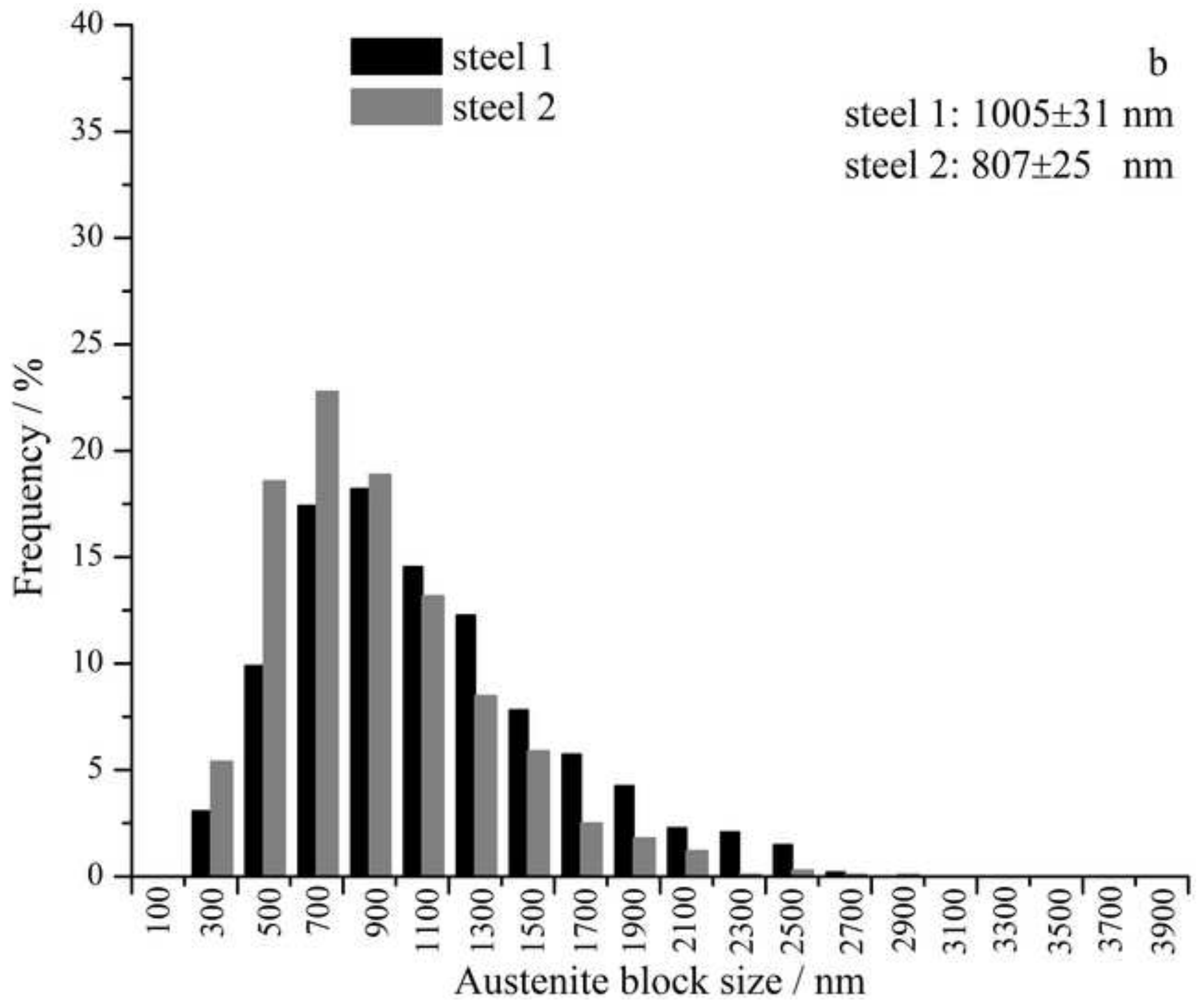




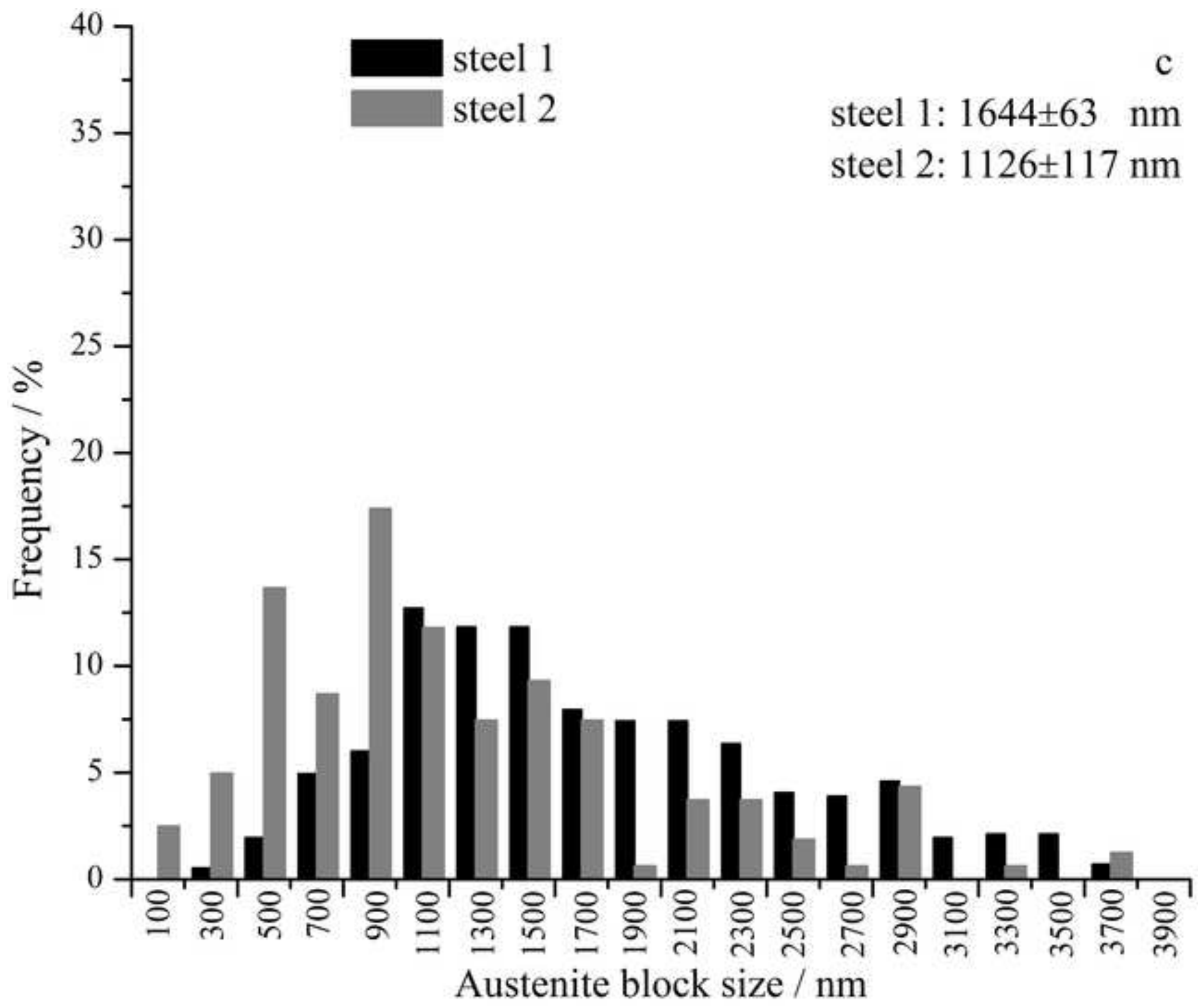




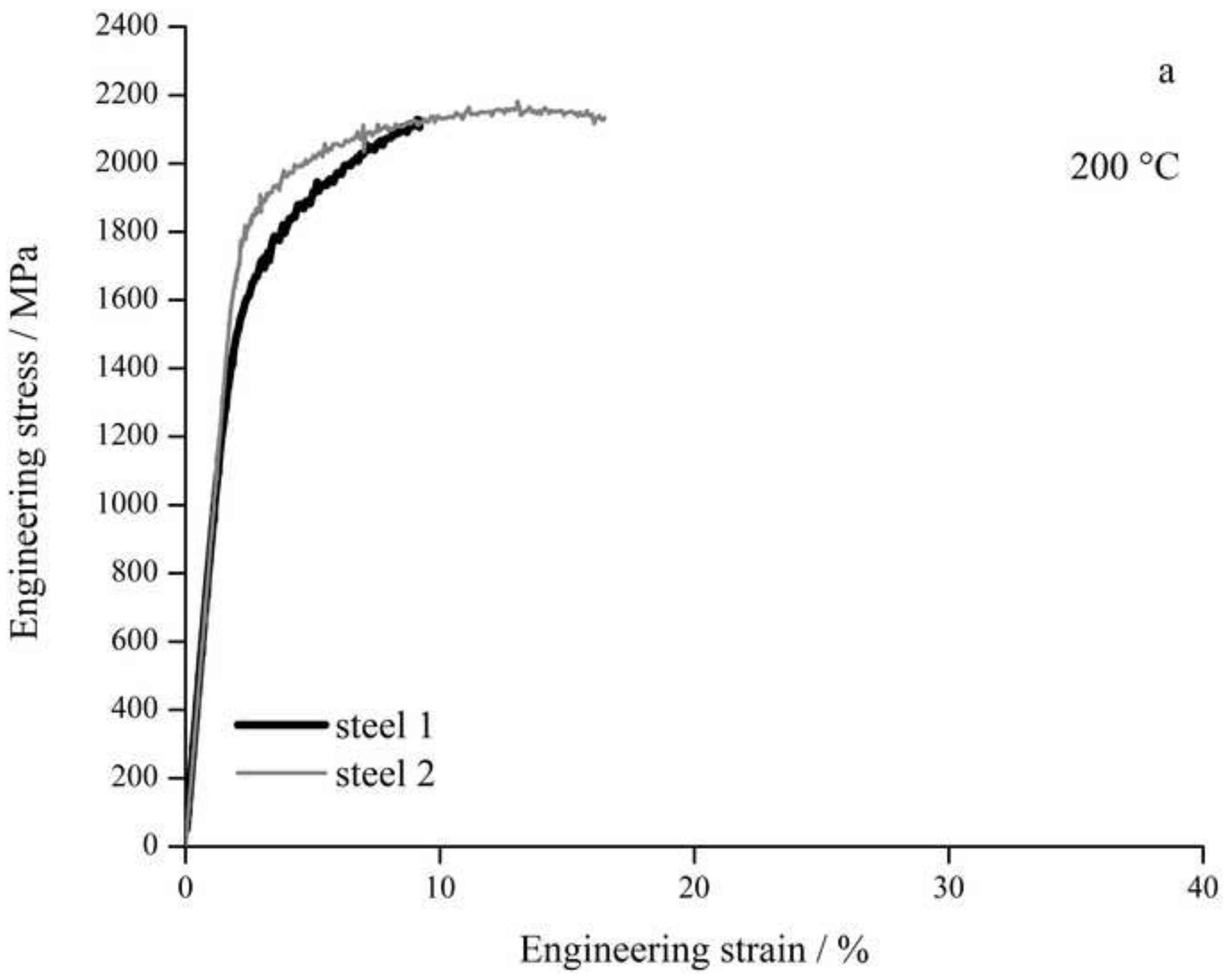




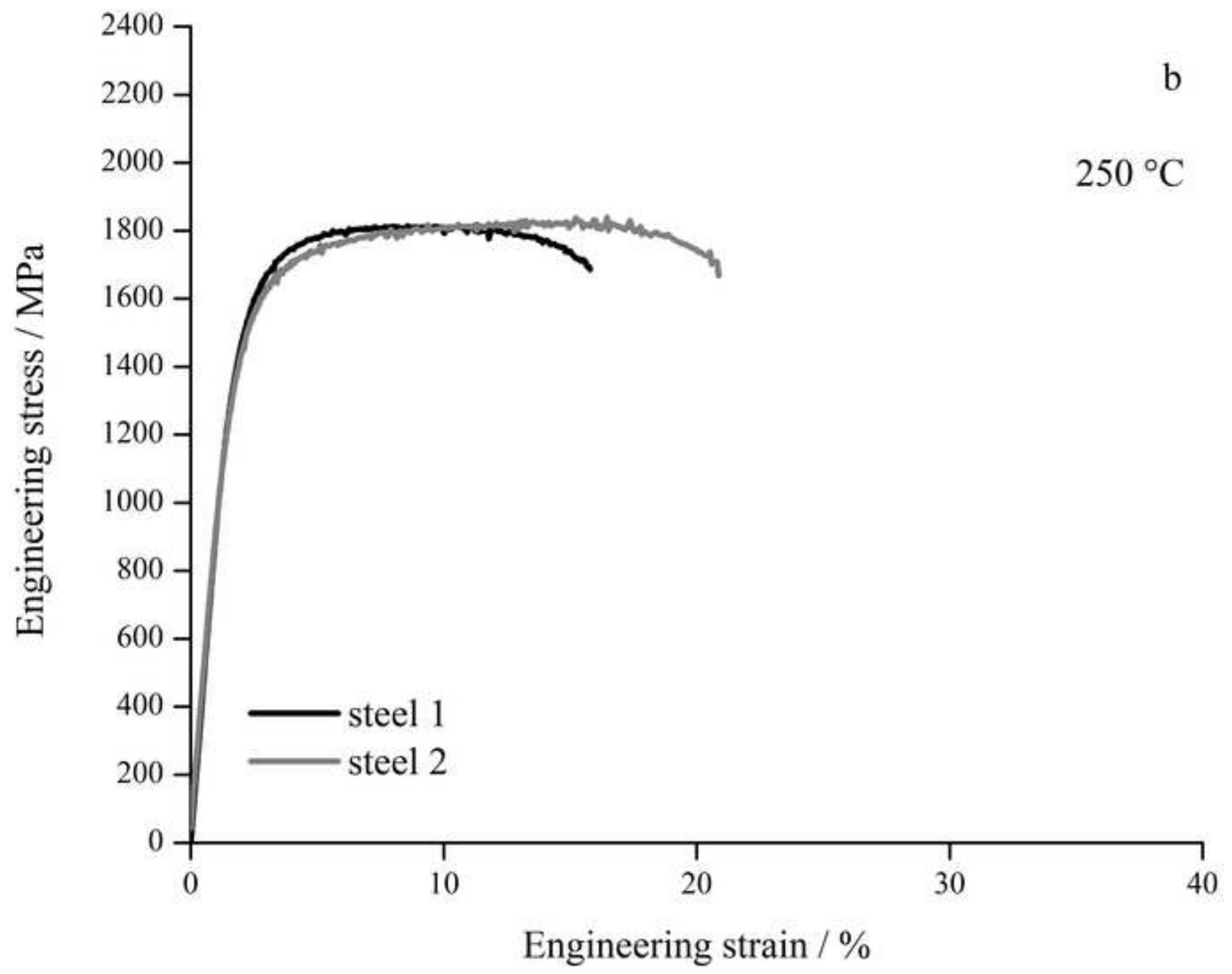




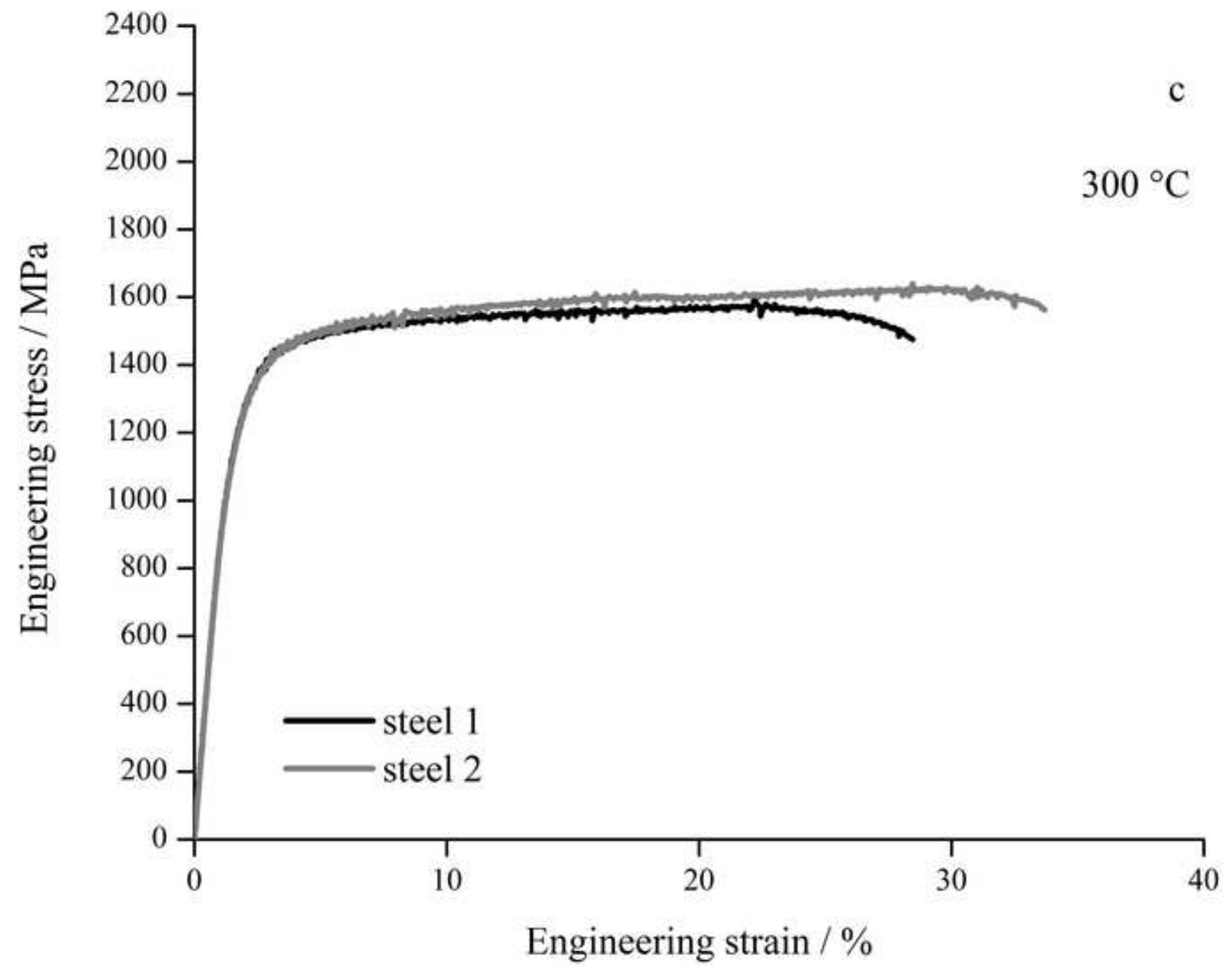




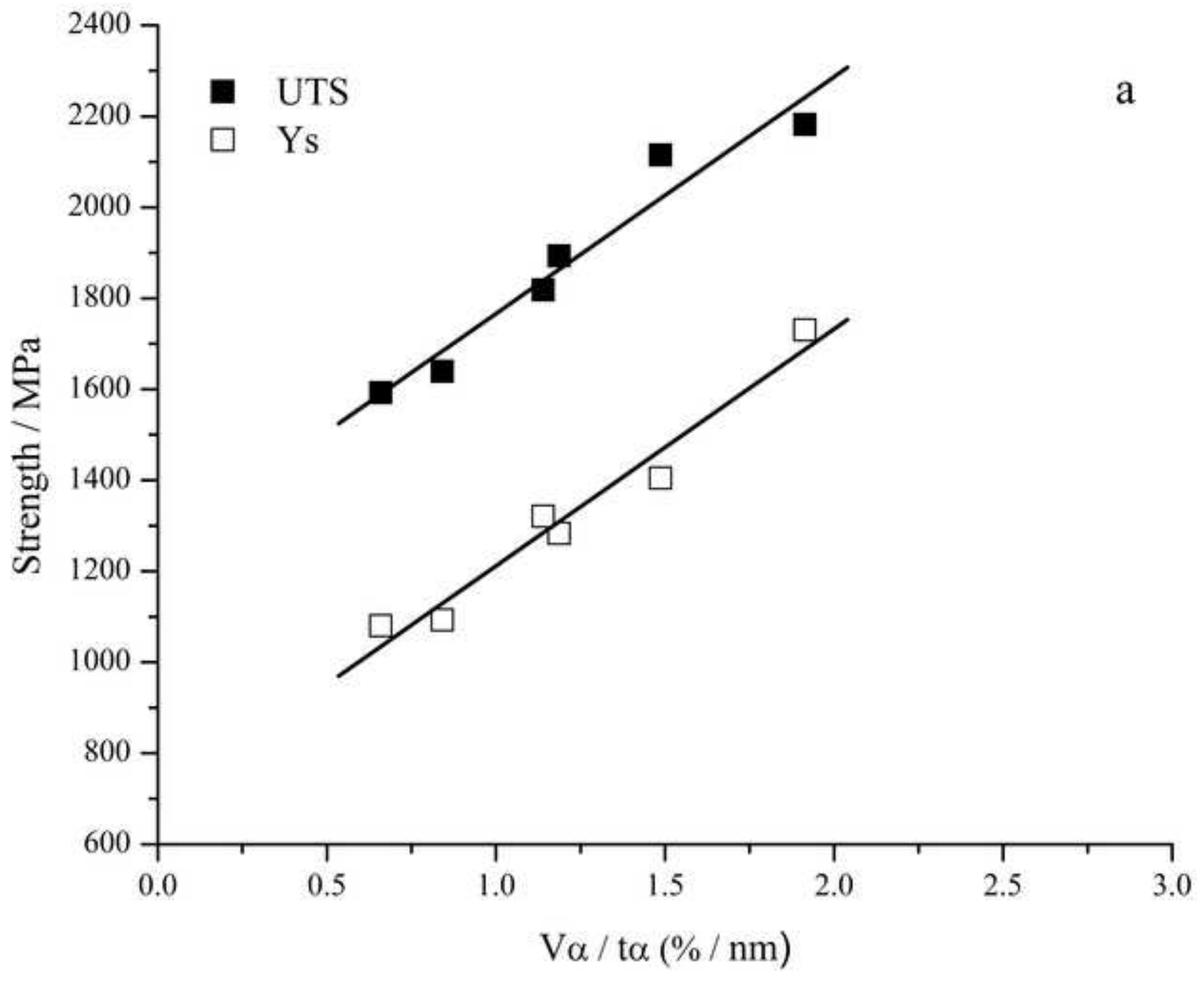




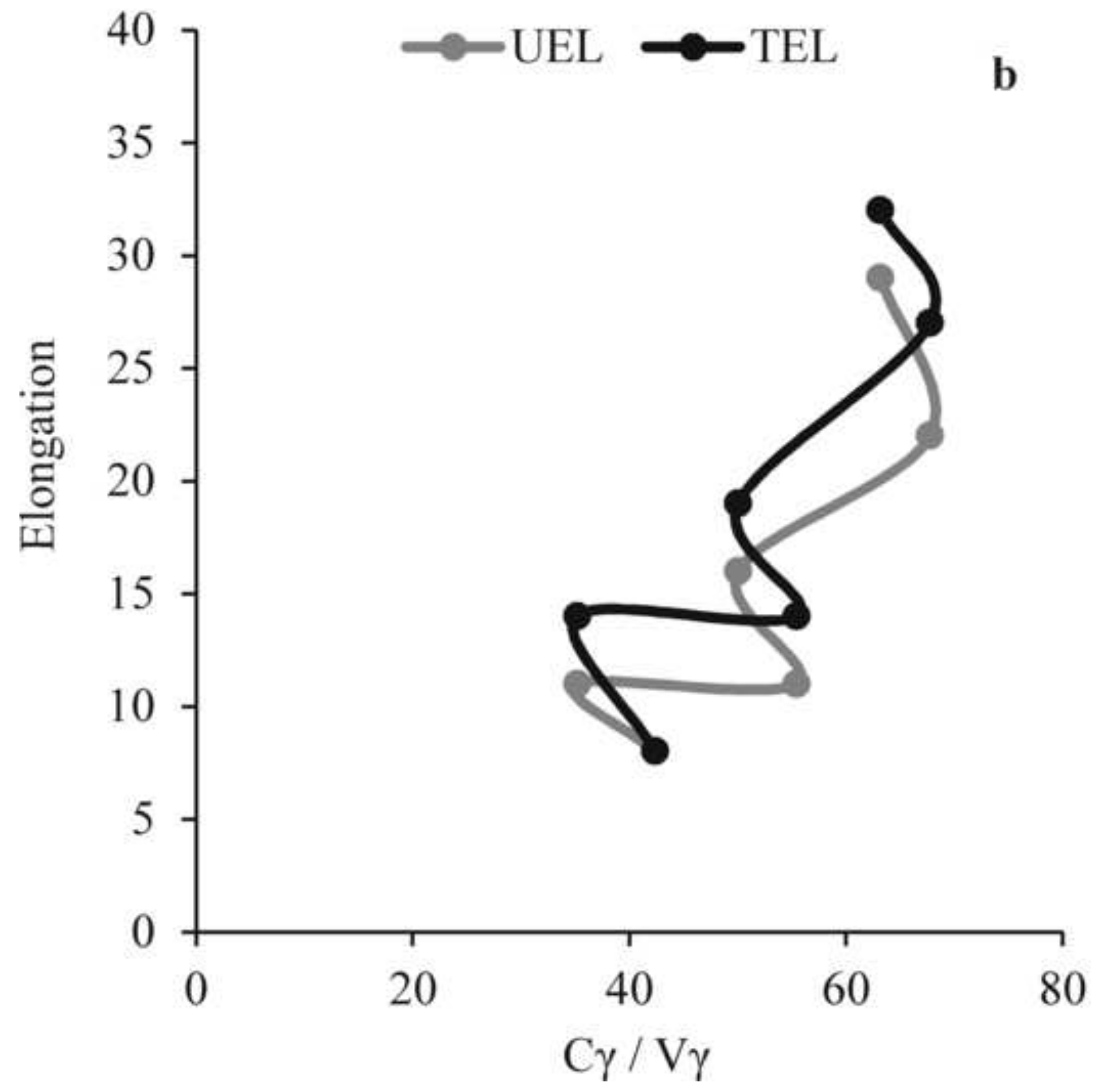




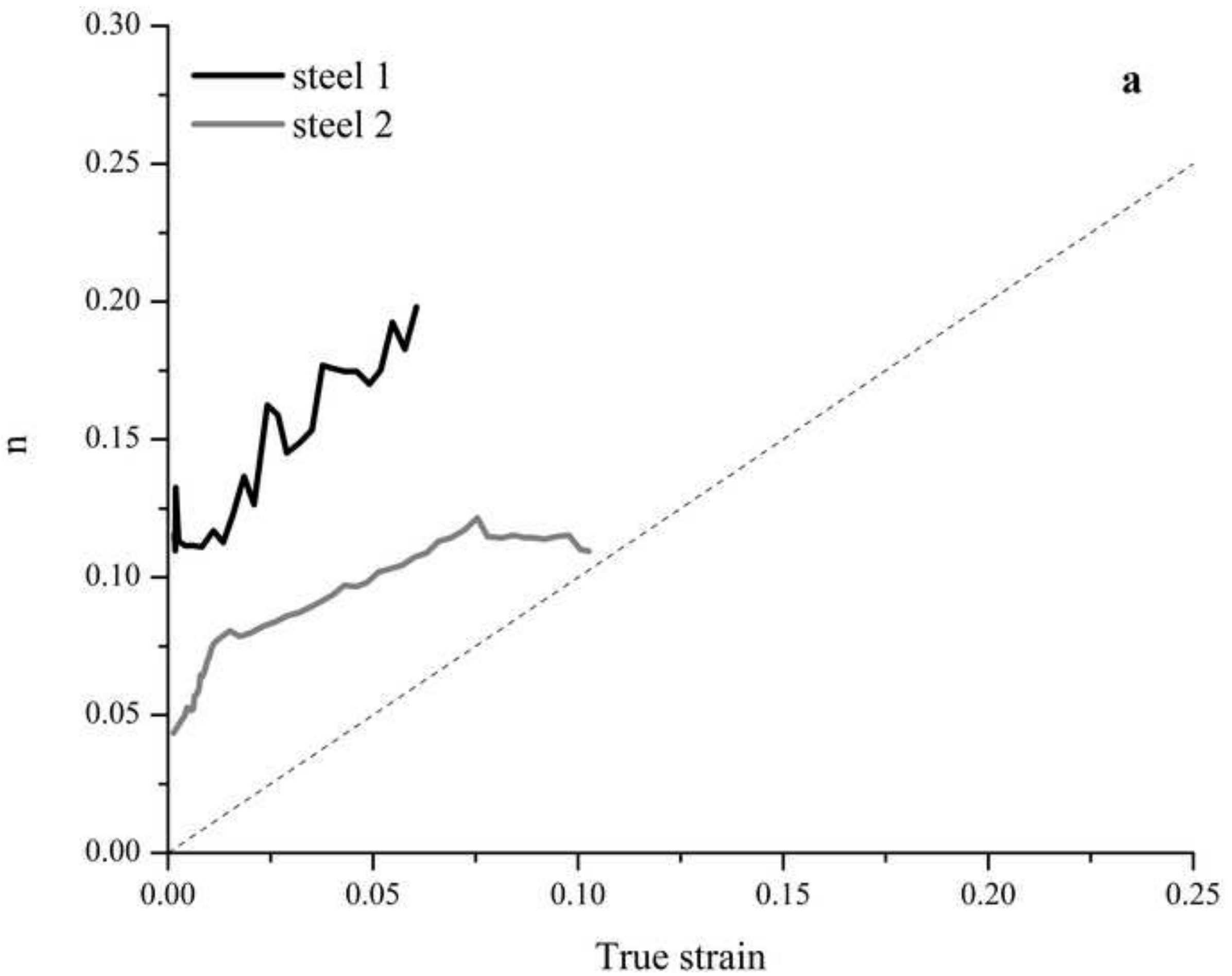




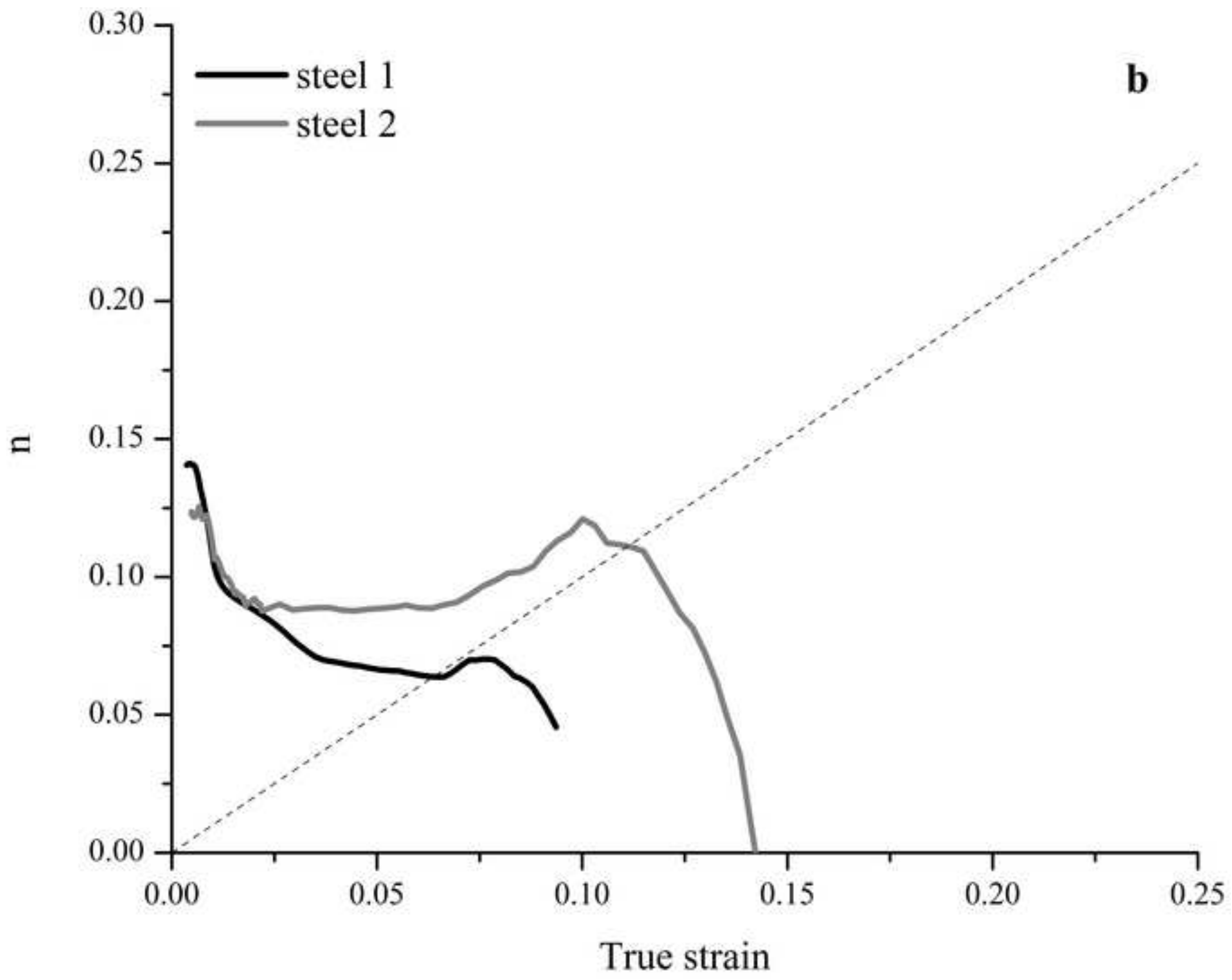




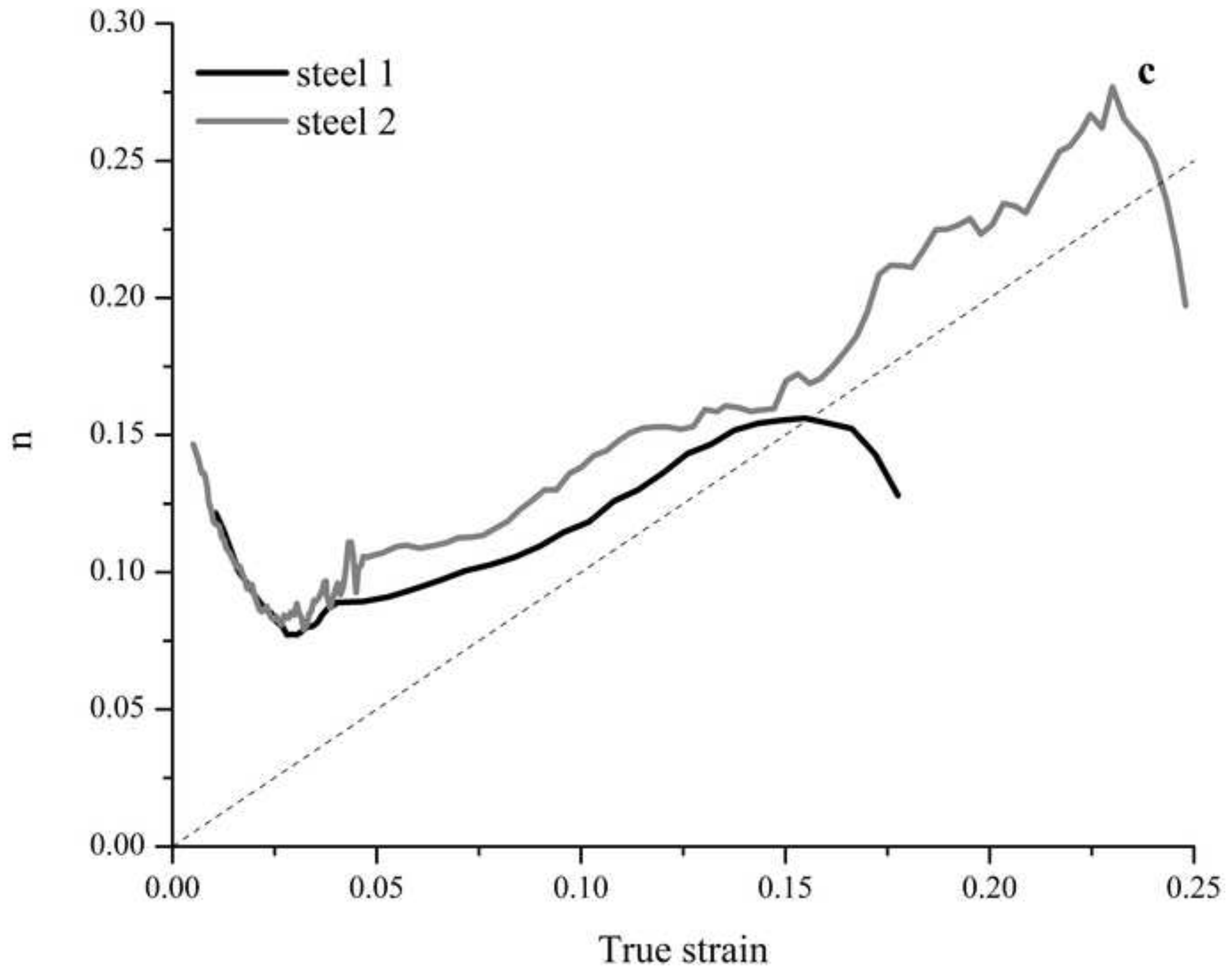


C

EP.

7.5.g. 582

n-cos

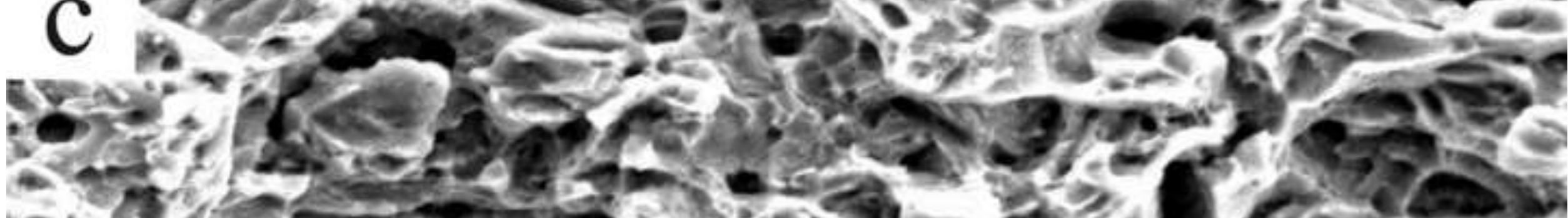

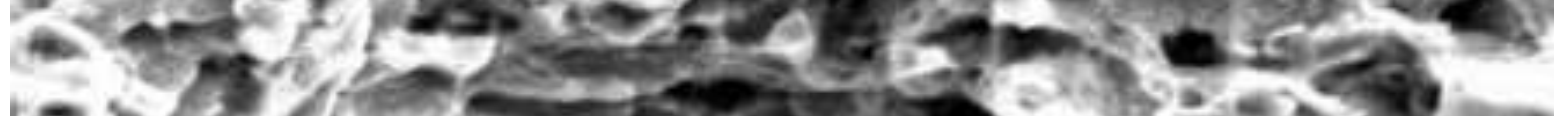

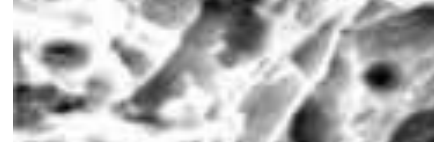

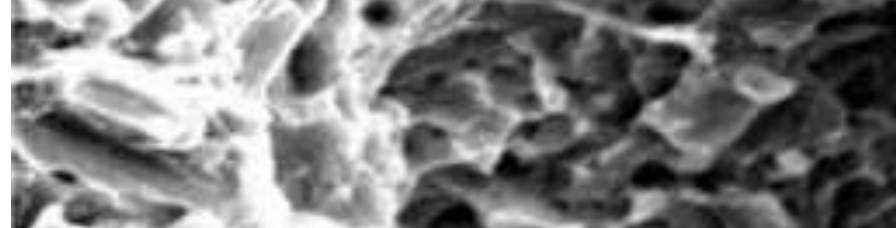

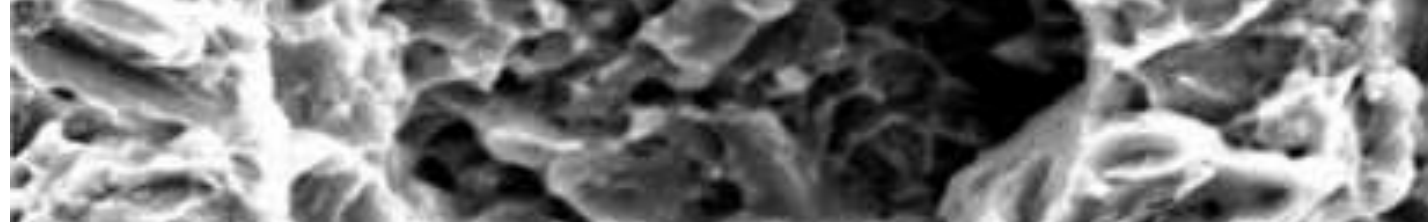

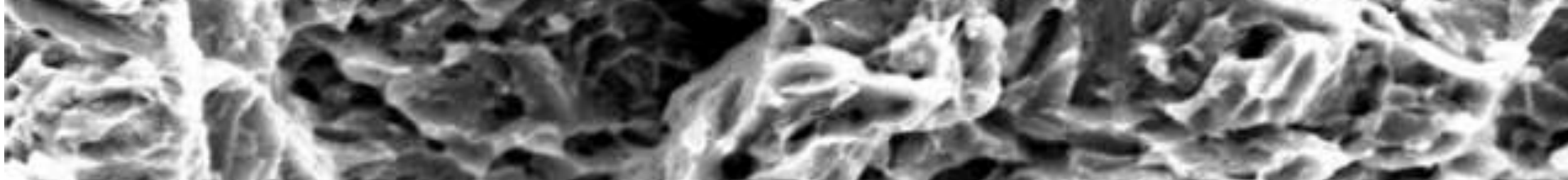

2.

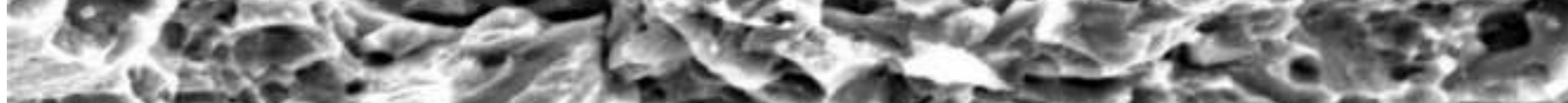

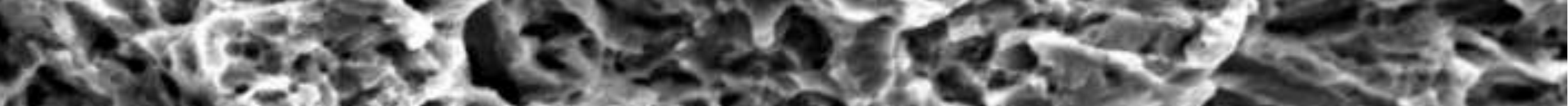
3
3

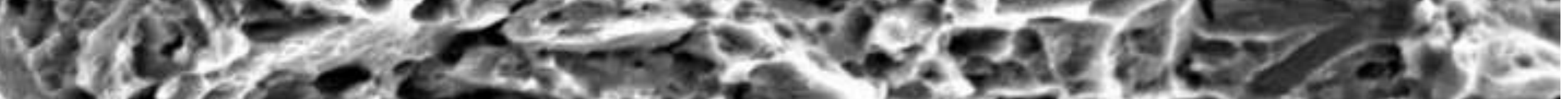

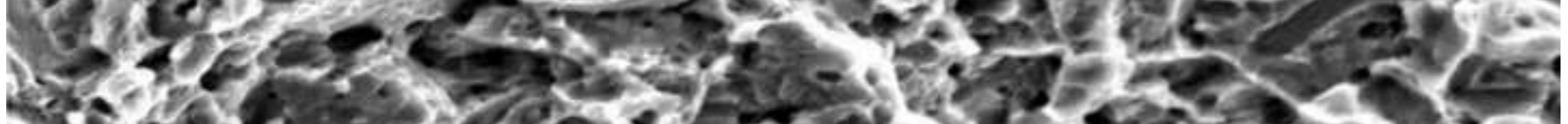

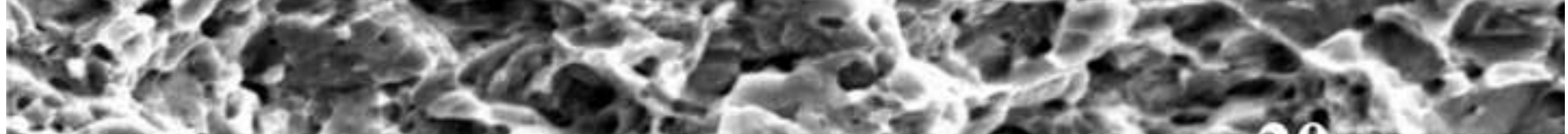

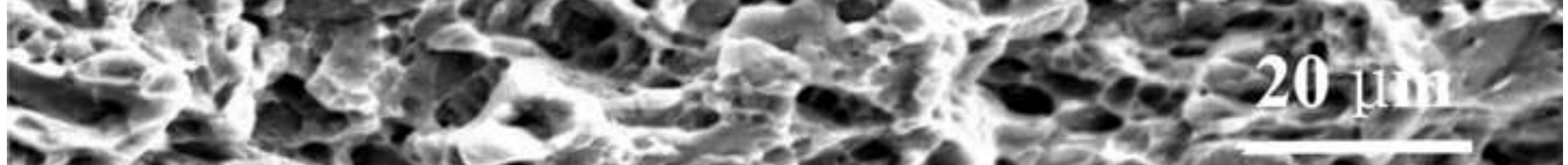
Pa 


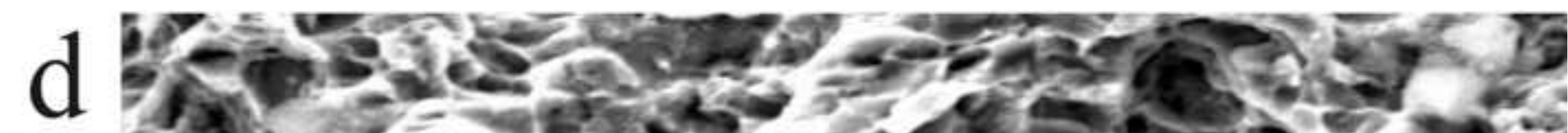
T.

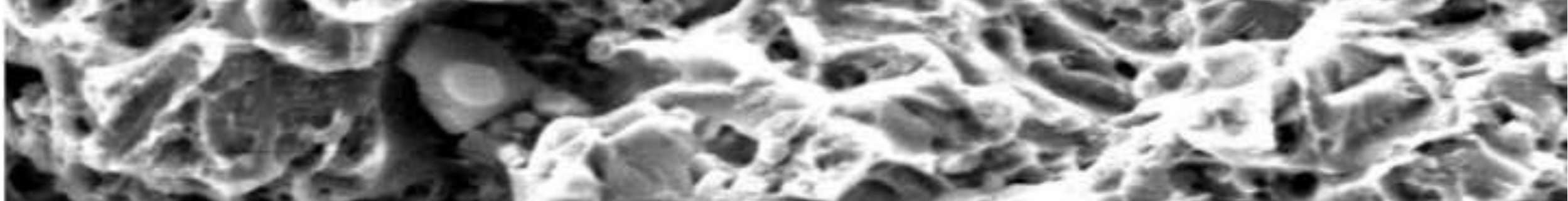

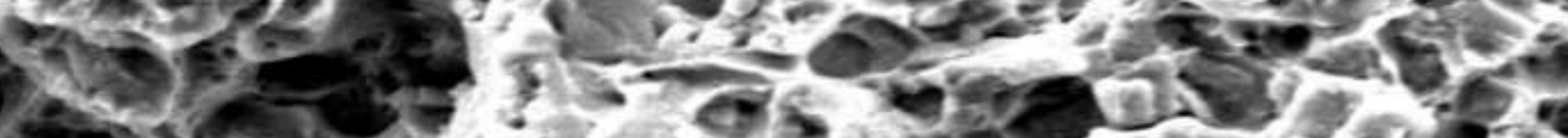

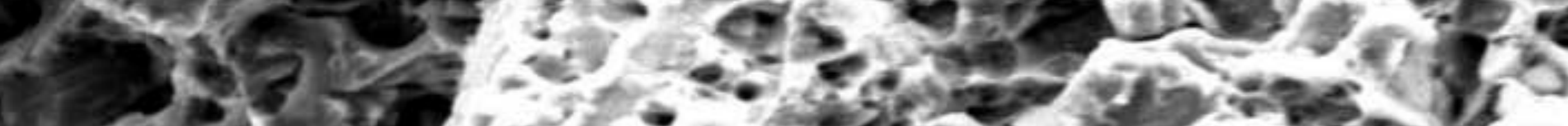

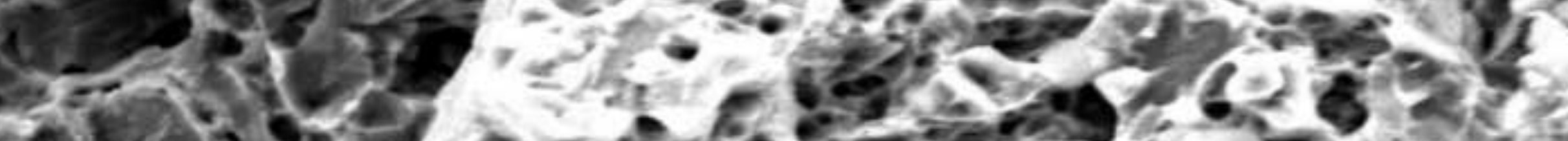

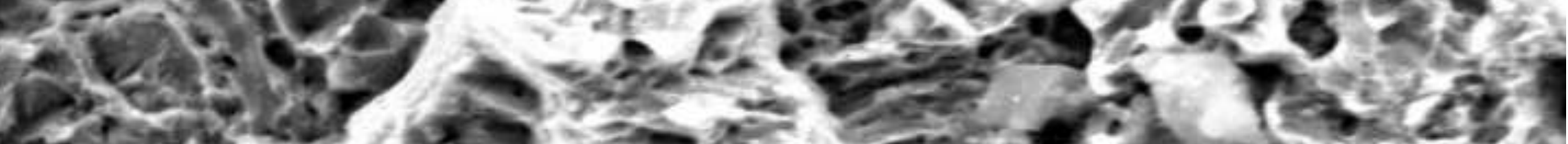

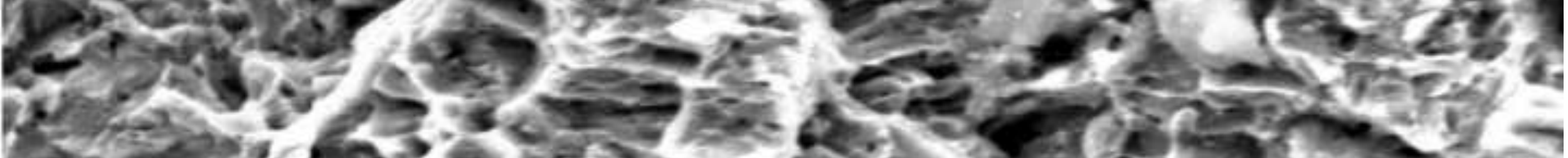

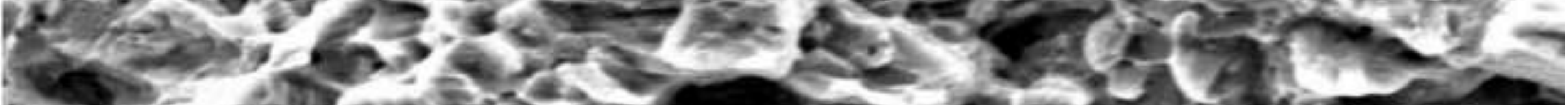

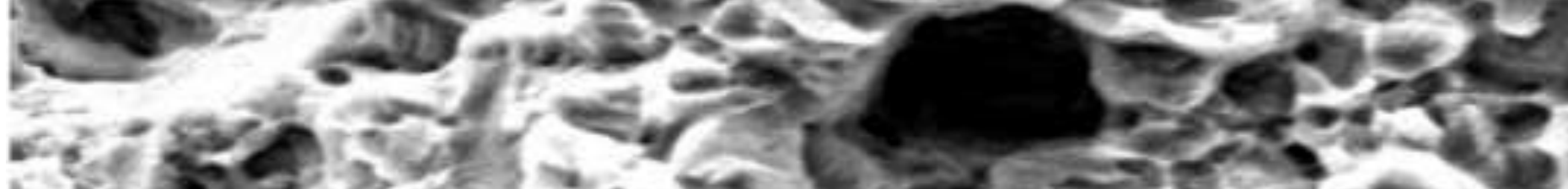
Isf

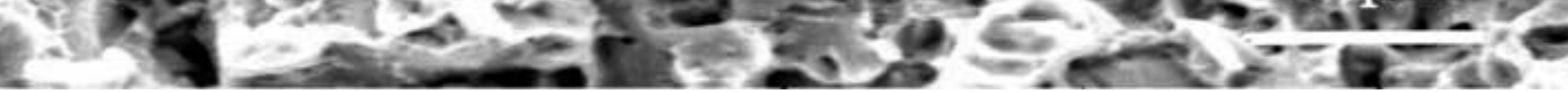

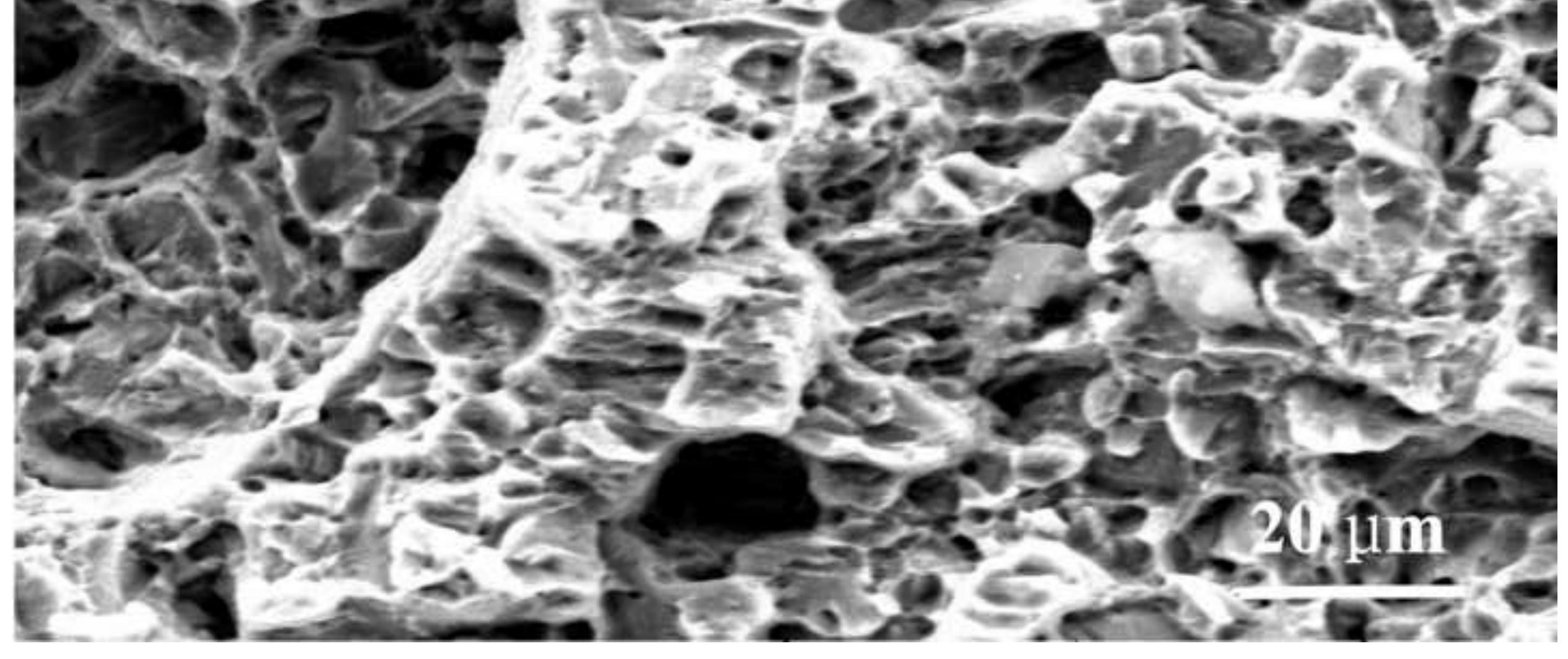

